NIST Technical Note 2022

\title{
Pool Boiling of HFO-1336mzz(Z) on a Reentrant Cavity Surface; Extensive Measurement and Analysis
}

\author{
Mark A. Kedzierski \\ Lingnan Lin
}

This publication is available free of charge from:

https://doi.org/10.6028/NIST.TN.2022

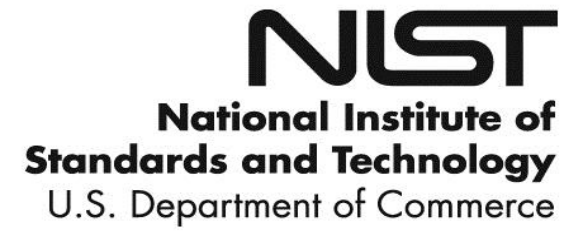


NIST Technical Note 2022

\title{
Pool Boiling of HFO-1336mzz(Z) on a Reentrant Cavity Surface; Extensive Measurement and Analysis
}

\author{
Mark A. Kedzierski \\ Lingnan Lin \\ Energy and Environment Division \\ Engineering Laboratory
}

This publication is available free of charge from:

https://doi.org/10.6028/NIST.TN.2022

October 2018

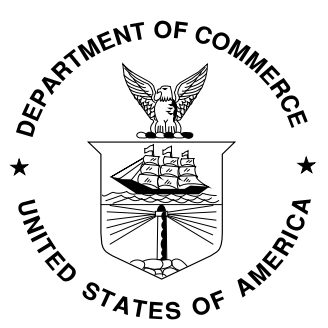

U.S. Department of Commerce

Wilbur L. Ross, Jr., Secretary

National Institute of Standards and Technology Walter Copan, NIST Director and Undersecretary of Commerce for Standards and Technology 
Certain commercial entities, equipment, or materials may be identified in this document in order to describe an experimental procedure or concept adequately. Such identification is not intended to imply recommendation or endorsement by the National Institute of Standards and Technology, nor is it intended to imply that the entities, materials, or equipment are necessarily the best available for the purpose.

National Institute of Standards and Technology Technical Note 2022

Natl. Inst. Stand. Technol. Tech. Note 2022, 43 pages (October 2018) CODEN: NTNOEF

This publication is available free of charge from:

https://doi.org/10.6028/NIST.TN.2022 


\title{
Pool Boiling of HFO-1336mzz(Z) on a Reentrant Cavity Surface; Extensive Measurement and Analysis
}

\author{
M. A. Kedzierski, and L. Lin \\ National Institute of Standards and Technology \\ Gaithersburg, MD 20899
}

\begin{abstract}
This paper quantifies the pool boiling performance of R1336mzz(Z), and R123 on a flattened, horizontal Turbo-ESP surface for heat fluxes between roughly $10 \mathrm{kWm}^{-2}$ and $120 \mathrm{kWm}^{-2}$. The study showed that the boiling performance of R1336mzz(Z) on the TurboESP did not differ statistically from that of R123 for heat fluxes between $13 \mathrm{kWm}^{-2}$ and $59 \mathrm{kWm}^{-2}$. For heat fluxes larger than $59 \mathrm{kWm}^{-2}$, the R123 boiling heat flux was up to $5 \%$ larger than the heat flux for R1336mzz(Z). For heat fluxes between $4 \mathrm{kWm}^{-2}$ and $13 \mathrm{kWm}^{-2}$, the R123 heat flux was approximately $53 \%$ larger than that of R1336mzz(Z). The R1336mzz $(Z)$ pool boiling curve was measured for three saturation temperatures and exhibited an optimum with respect to saturation temperature near the middle saturation temperature of $298.1 \mathrm{~K}$. A pool boiling model from the present authors was modified to include a single-phase transfer term and was used to predict both single-component and multi-component performance of the test refrigerants on the Turbo-ESP surface. For most heat fluxes, the modified model predicted the measured superheat to within $\pm 0.5 \mathrm{~K}$.
\end{abstract}

Keywords: boiling, enhanced heat transfer, refrigerants, structured surface 


\section{TABLE OF CONTENTS}

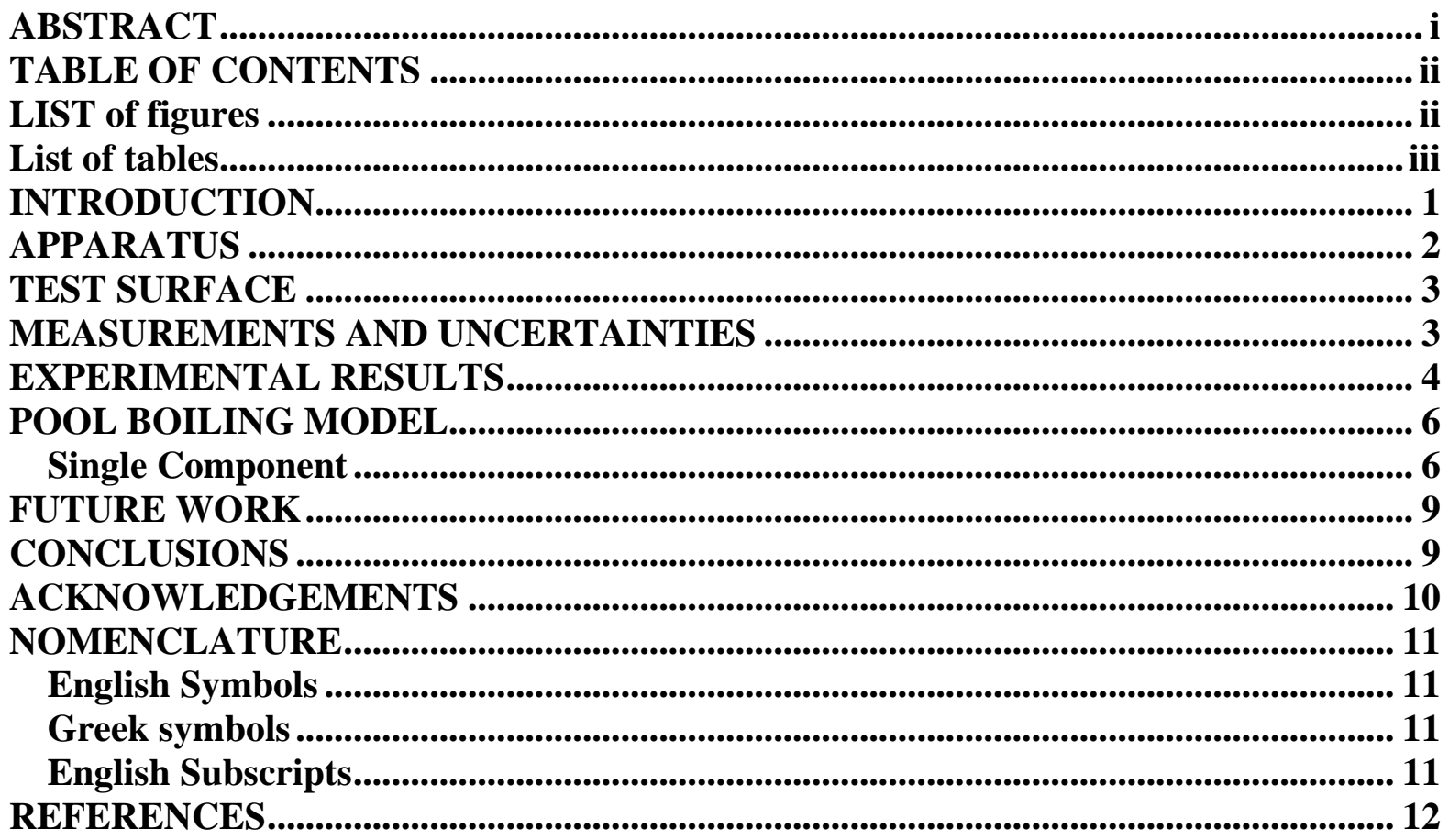

\section{LIST OF FIGURES}

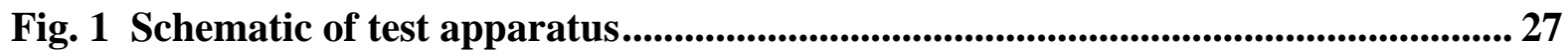

Fig. 2 OFHC copper flat test plate with Turbo-ESP surface and thermocouple coordinate system......................................................................................................................... 28

Fig. 3 Photograph of Turbo-ESP surface .................................................................................. 29

Fig. 4 Comparison of boiling curves for $R 123$ and $R 1336 m z z(Z)$ at $277.6 \mathrm{~K}$................. 30

Fig. 5 Comparison of $R 123$ heat flux to that for $R 1336 m z z(Z)$ at the same wall

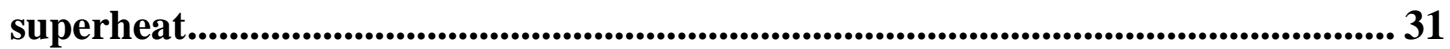

Fig. 6 Boiling curves for $R 1336 \mathrm{mzz}(Z)$ at different saturation temperatures................. 32

Fig. 7 Comparison of pool boiling model to $R 1336 \mathrm{mzz}(Z)$ for different saturation temperatures........................................................................................................... 33

Fig. 8 Comparison of pool boiling model for Turbo-ESP surface to present measurements for $R 123$ and $R 1336 \operatorname{mzz}(Z)$

Fig. 9 Comparison of pool boiling model for Turbo-ESP surface to present measurements for $R 1336 \mathrm{mzz}(\mathrm{Z})$, and Kedzierski et al. (2018) measurements for R134a and R1234yf.

Fig. A.1 Expanded relative uncertainty in the heat flux of the surface at the $95 \%$ confidence level...................................................................................................................... 36

Fig. A.2 Expanded uncertainty in the temperature of the surface at the $95 \%$ confidence level. 


\section{LIST OF TABLES}

Table 1 Conduction model choice......................................................................................... 15

Table 2 Pool boiling data.......................................................................................... 16

Table 3 Number of test days and data points ............................................................... 22

Table 4 Estimated parameters for cubic boiling curve fits ............................................ 23

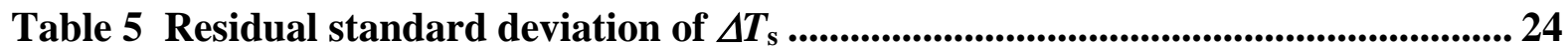

Table 6 Average magnitude of $95 \%$ multi-use confidence interval for mean $\Delta T_{\mathrm{s}} \ldots . . . . .25$

Table 7 Selected fluid properties of test refrigerants at saturation (Lemmon et al.,

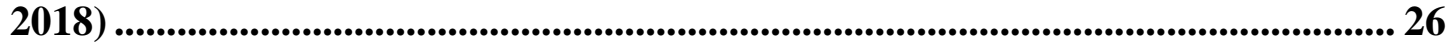




\section{INTRODUCTION}

The required characteristics of refrigerants used as working fluids are rigorous and numerous. A refrigerant must meet the required temperature, pressure, enthalpy, and heat transfer characteristics while remaining stable and not harming the environment. Policies set by the European F-gas Regulation (EU, 2014), and the Kigali amendment to the Montreal Protocol (UNEP, 2016) are designed to protect the environment by encouraging the use of refrigerants with low global warming potential (GWP). These policies along with the Montreal Protocol (1987) concerning ozone depletion potential (ODP), have caused a recent shift to refrigerants with both zero ODP and low-GWP. Refrigerant R123 (ODP = 0.02 (WMO, 2006)) is a low-pressure refrigerant with a relatively small 100-year horizon $\mathrm{GWP}^{1}$ of 79 (Myhre et al., 2013) that has been used chiefly in water chillers that cool large buildings. Refrigerant R1336mzz(Z) was originally developed for use as an expansion agent for polyurethane foam (Wysong, et al. (2014) and Loh et al., 2014), but may potentially be used as a replacement for R123 in water chillers (Kontomaris, 2010). ${ }^{2}$ The new refrigerant R1336mzz(Z) has the advantage over R123 of a lower GWP of 2 (Myhre et al., 2013) and more applications as a working fluid due to its chemical stability at higher temperatures (Kontomaris, 2013, 2011). For example, Kontomaris (2014a) identified one higher temperature application for $\mathrm{R} 1336 \mathrm{mzz}(\mathrm{Z})$ in an organic Rankine cycle for industrial waste heat recovery and another as a working fluid for high temperature heat pumps (Kontomaris, 2014b).

Rogers (1961) identified the origin of the commercial application of refrigerant-shell-side enhancements to water chillers as occurring around 1938. These original augmentations were rectangularly finned tubes with rather low fin densities. Since then, the shell-side augmentation for refrigeration has evolved toward more complicated fin shapes and larger fin densities. For example, 1971 saw the introduction of a commercial boiling tube that was made specifically for the promotion of reentrant boiling, which was achieved by using a "bent fin" (Kedzierski, 1999). The US patent 3,696,861 (Webb, 1972) for the bent fin was a simple modification of the rectangularly finned tube by raking the fins back upon themselves producing a specified gap between the fin-tip and the adjacent fin for escaping bubbles. Further evolution of enhanced boiling tube technology has led to significantly more intricate surfaces than the bent-fin. This paper investigates the heat transfer performance of R1336mzz(Z) on one of the newer boiling surfaces, i.e., Turbo-ESP ${ }^{3}$.

As expected considering its recent introduction, relatively few studies involving $\mathrm{R} 1336 \mathrm{mzz}(\mathrm{Z})$ are in the literature. A few boiling investigations for refrigerants have been done for mechanically formed reentrant cavity surfaces that are similar to the structure of the Turbo-ESP surface. Lee et al. (2014) presented boiling heat transfer measurements for R1234yf and R134a on a flat plain, a Turbo-B, a Turbo-C, and a Thermoexcel-E surface. For all tested heat fluxes, their measurements showed that the boiling heat transfer coefficient for each surface was nearly the same for R1234yf and R134a. Gorgy and Eckels (2010) presented measurements of pool boiling of R134a and R123 on Turbo-BII-HP and Turbo-BII-LP tube bundles, respectively, as well as on smooth tube bundles. Gorgy and Eckels (2012) present experimental investigation of pool boiling on Turbo-BII-HP and Turbo-BII-LP single tubes for R134a and R123, respectively.

\footnotetext{
${ }^{1}$ All GWP values are given for zero contribution from climate-carbon feedbacks.
} 
The only boiling measurements that were found in the literature for the Turbo-ESP surface were by Gorgy (2016). Gorgy (2016) presented an experimental investigation of the heat transfer performance of R123, R134a, R1234ze, R1233zd(E), and R450A on the Turbo-ESP. The results show that the performance of R1234ze is very similar to that of R134a while R450A shows performance degradation of $28 \%$ compared to R134a. The boiling heat transfer for R1233zd(E) was 19\% greater than that for R123. Kedzierski et al. (2018) quantified the pool boiling performance of R134a, R1234yf, R513A, and R450A on a flattened, horizontal TurboESP surface. Their study showed that the boiling performance of R134a on the Turbo-ESP exceeded that of the replacement refrigerants for heat fluxes greater than $20 \mathrm{kWm}^{-2}$. On average, the heat flux for R1234yf and R513A was $16 \%$ and $19 \%$ less than that for R134a, respectively, for R134a heat fluxes between $20 \mathrm{kWm}^{-2}$ and $110 \mathrm{kWm}^{-2}$.

Because of the relatively recent introduction of $\mathrm{R} 1336 \mathrm{mzz}(\mathrm{Z})$, the availability of measured pool boiling heat transfer data given in the literature is limited for this refrigerant. Only two studies for the Turbo-ESP surface (Gorgy (2016) and Kedzierski et al, 2018), which did not include the performance of $\mathrm{R} 1336 \mathrm{mzz}(\mathrm{Z})$, exist in the literature. Consequently, the present study provides pool boiling heat transfer measurements for R123, and R1336mzz(Z) on the horizontal, flat, copper, Turbo-ESP-finned surface for test conditions that are applicable for air-conditioning applications. In addition, $\mathrm{R} 1336 \mathrm{mzz}(\mathrm{Z})$ is tested at higher temperatures for industrial heat recovery applications.

\section{APPARATUS}

Figure 1 shows a schematic of the apparatus that was used to collect the pool boiling data. More specifically, the apparatus was used to measure the liquid saturation temperature $\left(T_{\mathrm{s}}\right)$, the average pool-boiling heat flux $\left(q^{\prime \prime}\right)$, and the wall temperature $\left(T_{\mathrm{w}}\right)$ of the test surface. The three principal components of the apparatus were a test chamber containing the test surface, the condenser, and the purger. The internal dimensions of the test chamber were $25.4 \mathrm{~mm} \times$ $257 \mathrm{~mm} \times 1.54 \mathrm{~m}$. The test chamber was charged with approximately $7 \mathrm{~kg}$ of refrigerant, giving a liquid height of approximately $80 \mathrm{~mm}$ above the test surface. As shown in Fig. 1, the test section was visible through two opposing, flat $150 \mathrm{~mm} \times 200 \mathrm{~mm}$ quartz windows. The bottom of the test surface was heated with high velocity $(2.5 \mathrm{~m} / \mathrm{s})$ water flow. The vapor produced by liquid boiling on the test surface was condensed by the brine-cooled, shell-andtube condenser and returned as liquid to the pool by gravity. Further details of the test apparatus can be found in Kedzierski (2002) and Kedzierski (2001).

\footnotetext{
${ }^{2}$ Improvements in the thermodynamic characteristics of $\mathrm{R} 1336 \mathrm{mzz}(\mathrm{Z})$ as they apply to chillers have been made by blending it with trans-1,2 dichloroethylene, which creates an azeotropic mixture R514A (74.7/25.3, R1336mzz(Z)/R-514A by mass).

${ }^{3}$ Certain trade names and company products are mentioned in the text or identified in an illustration in order to adequately specify the experimental procedure and equipment used. In no case does such an identification imply recommendation or endorsement by the National Institute of Standards and Technology, nor does it imply that the products are necessarily the best available for the purpose.
} 


\section{TEST SURFACE}

Figure 2 shows the oxygen-free high-conductivity (OFHC) copper flat test plate used in this study. The test plate was machined out of a single piece of OFHC copper by electric discharge machining (EDM). The internal fins of a commercial $25 \mathrm{~mm}$ (outer-diameter) Turbo-ESP tube were removed by EDM. The tube was then cut axially, annealed, flattened, and soldered onto the top of the test plate. Figure 3 shows a photograph of the fin surface. The Turbo-ESP has approximately 1968 fins per meter (fpm) oriented along the short axis of the plate. The overall fin-height and the width of the surface openings at the fin-tips are approximately $0.4 \mathrm{~mm}$ and $0.04 \mathrm{~mm}$, respectively.

\section{MEASUREMENTS AND UNCERTAINTIES}

The standard uncertainty is the square root of the estimated variance. The individual standard uncertainties are combined to obtain the expanded uncertainty $(U)$, which is calculated from the law of propagation of uncertainty with a coverage factor. All measurement uncertainties are reported at the $95 \%$ confidence level except where specified otherwise. Further detail on the heat transfer measurement uncertainties can be found in Appendix A.

All of the copper-constantan thermocouples and the data acquisition system were calibrated against a glass-rod standard platinum resistance thermometer (SPRT) and a reference voltage to a residual standard deviation of $0.005 \mathrm{~K}$. The reference voltage enabled the correction of any drift in the voltage measurement over time. Considering the fluctuations in the saturation temperature during the test and the standard uncertainties in the calibration, the expanded uncertainty of the average saturation temperature was no greater than $0.04 \mathrm{~K}$. Consequently, it is estimated that the expanded uncertainty of the temperature measurements was less than $0.1 \mathrm{~K}$.

Twenty $0.5 \mathrm{~mm}$ diameter thermocouples were force fitted into the wells of the side of the test plate shown in Fig. 2. The heat flux and the wall temperature were obtained by regressing the measured temperature distribution of the block to the governing two-dimensional conduction equation (Laplace equation). In other words, rather than using the boundary conditions to solve for the interior temperatures, the interior temperatures were used to solve for the boundary conditions following a backward stepwise procedure given in Kedzierski $(1995)^{4}$. As shown in Fig. 2, the origin of the coordinate system was centered on the surface with respect to the y-direction at the heat transfer surface. Centering the origin in the ydirection reduced the uncertainty of the wall heat flux and temperature calculations by reducing the number of fitted constants involved in these calculations.

Fourier's law and the fitted constants from the Laplace equation were used to calculate the average heat flux $\left(q^{\prime \prime}\right)$ normal to and evaluated at the heat transfer surface based on its projected area. The average wall temperature $\left(T_{\mathrm{w}}\right)$ was calculated by integrating the local wall temperature $(T)$. The wall superheat was calculated from $T_{\mathrm{w}}$ and the measured temperature of the saturated liquid $\left(T_{\mathrm{s}}\right)$. Considering this, the relative expanded uncertainty

\footnotetext{
${ }^{4}$ Table 1 provides functional forms of the Laplace equation that were used in this study in the same way as was done in Kedzierski (1995) and in similar studies by this author.
} 
in the heat flux $\left(U_{q^{\prime \prime}}\right)$ was greatest at the lowest heat fluxes, approaching $12 \%$ of the measurement near $10 \mathrm{kWm}^{-2}$. In general, the $U_{q^{\prime \prime}}$ remained between $3 \%$ and $7 \%$ for heat fluxes greater than $20 \mathrm{kWm}^{-2}$. The average random error in the wall superheat ( $\left.U_{\mathrm{Tw}}\right)$ remained mainly between $0.06 \mathrm{~K}$ and $0.1 \mathrm{~K}$ with an average value of approximately $0.085 \mathrm{~K}$. Plots of $U_{q^{\prime \prime}}$ and $U_{\mathrm{Tw}}$ versus heat flux can be found in Appendix A.

\section{EXPERIMENTAL RESULTS}

The heat flux was varied between $10 \mathrm{kWm}^{-2}$ and $120 \mathrm{kWm}^{-2}$ to simulate a range of possible operating conditions for R123 chillers. Pool-boiling measurements were made at a saturated temperature of $277.6 \mathrm{~K}$ for R123 and at $277.6 \mathrm{~K}, 298.1 \mathrm{~K}$, and $318.1 \mathrm{~K}$ for R1336mzz(Z). The data were recorded consecutively starting at the largest heat flux and descending in intervals of approximately $4 \mathrm{kWm}^{-2}$. The descending heat flux procedure minimized the possibility of observing any hysteresis effects on the data, which would have made the data sensitive to the initial operating conditions. Check out tests with R134a were done prior to each new study to ensure that the present boiling performance closely repeated previous measurements with R134a. Table 2 presents the measured heat flux and wall superheat for all the data of this study. Table 3 gives the number of test days and data points for each fluid. A total of 937 measurements were made over 33 days.

Figure 4 is a plot of the measured boiling heat flux $\left(q^{\circ}\right)$ versus the measured wall superheat $\left(T_{\mathrm{w}}-T_{\mathrm{s}}=\Delta T_{\mathrm{s}}\right)$ for R123 and R1336mzz(Z) on the Turbo-ESP at a saturation temperature of $277.6 \mathrm{~K}$. The open circles and open squares represent the measured data for R123 and R1336mzz(Z), respectively. The solid line is a cubic best-fit regression or estimated mean of the data. Seven test days with R123 produced 189 measurements over a period of ten days. Six of the 189 measurements were removed before fitting because they were statistically identified as "outliers" based on having both high influence and high leverage (Belsley et al., 1980). The data sets for each test fluid presented in this manuscript exhibited a similar number of outliers and were regressed in the same manner. Surface aging data (i.e., "breakin" data) also were not included in the analyzed data sets. The surface aging data typically occurred for each fluid over the first or first and second test days and deviated significantly from the mean of the succeeding and consecutive measurements made over eight to 23 days. Surface aging was not observed over the included data because the between-run variation was approximately random.

Table 4 gives the constants for the cubic regression of the superheat versus the heat flux for all of the fluids tested here. The residual standard deviation of the regressions - representing the proximity of the data to the mean - are given in Table 5 and are, on average, approximately $0.06 \mathrm{~K}$. The dashed lines to either side of the mean boiling curve (solid line) represent the lower and upper $95 \%$ simultaneous (multiple-use) confidence intervals for the mean and are, for much of the data, concealed by the data symbols. From the confidence intervals, the expanded uncertainty of the estimated mean wall superheat was, on average, $0.03 \mathrm{~K}$. Table 6 provides the average magnitude of the $95 \%$ multi-use confidence interval for the fitted wall superheat for all of the test data. Table 7 provides selective fluid properties for the test refrigerants evaluated with REFPROP (Lemmon, et al., 2018) at the saturation test temperature for each test fluid. 
Figure 4 compares pool boiling measurements of the present study to those of Gorgy (2016) for R123 on the Turbo-ESP surface at a saturation temperature of $277.6 \mathrm{~K}$. The Gorgy (2016) R123 measurements are represented by a large-dashed black line. The line was produced by using a correlated fit that was provided in Gorgy (2016). The Gorgy (2016) measurements were obtained by means of a Wilson (1915) plot for a test section consisting of three $914 \mathrm{~mm}$ long, water cooled tubes in a $245 \mathrm{~mm}$ diameter shell. For the same wall superheat, the Gorgy (2016) heat flux for R123 is on average approximately $36 \%$ less than the heat flux measured in the present study for R123. The maximum deviation occurs at a wall superheat of approximately $2 \mathrm{~K}$ for R123 where the Gorgy (2016) measurements are approximately $43 \%$ less than the present measured heat fluxes. The best agreement for R123 is for wall superheats less than $1.0 \mathrm{~K}$ where the two measurement sets are within $10 \%$. Some of the difference between the present measurements and those of Gorgy (2016) may be attributed to manufacturing tolerances between the two test surfaces; the effect of averaging heat fluxes over different test section lengths; an indirect versus a direct measurement method; and a round tube versus a flat test section. Considering the potential sources for differences, it is believed that the above comparison corroborates the validity of the measurements for R123 on the Turbo-ESP surface because the superheats for the two studies are within $1 \mathrm{~K}$.

Figure 5 shows a more precise illustration of the relative boiling heat transfer rate of R123 and $\mathrm{R} 1336 \mathrm{mzz}(\mathrm{Z})$ that is given in Fig. 4 for $T_{\mathrm{s}}=277.6 \mathrm{~K}$. Figure 5 plots the ratio of the $\mathrm{R} 123$ heat flux to the R1336mzz(Z) heat flux at the same wall superheat. The heat flux ratio is shown as a solid line with dashed lines and shaded regions representing the $95 \%$ multi-use confidence level for each mean. A heat transfer degradation exists where the heat flux ratio is less than one and the $95 \%$ simultaneous confidence intervals (depicted by the shaded regions) do not include the value one. The minimum heat flux ratio for the pair was $0.94 \pm 0.036$, which occurred at a heat flux near $34.4 \mathrm{kWm}^{-2}$. For heat fluxes between $12 \mathrm{kWm}^{-2}$ and $65 \mathrm{kWm}^{-2}$, a difference between the boiling performance of R123 and R1336mzz(Z) was not statistically significant. On average the heat flux for R123 was approximately $6 \%$ larger than that of $\mathrm{R} 1336 \mathrm{mzz}(\mathrm{Z})$ for the entire range of heat fluxes that were measured. The maximum heat flux ratio was $2.38 \pm 0.25$ at a heat flux of approximately $4.2 \mathrm{kWm}^{-2}$. The $138 \%$ larger heat flux for $\mathrm{R} 123$ at $4.2 \mathrm{kWm}^{-2}$ corresponds to approximately a $0.1 \mathrm{~K}$ smaller superheat than that for $\mathrm{R} 1336 \mathrm{mzz}(\mathrm{Z})$. This is probably due to the slightly smaller surface tension of R123 as compared to R1336mzz(Z), as shown in Table 7 , which would lead to smaller superheat requirements for bubble initiation. At very low heat fluxes, bubble initiation governs boiling performance due to the insignificant interaction between bubbles and the interaction between bubbles and the boiling surface fin canopy.

Figure 6 compares the pool boiling heat flux $\left(q^{\prime \prime}\right)$ versus the wall superheat $\left(T_{\mathrm{w}}-T_{\mathrm{s}}\right)$ for the Turbo-ESP surface measured in this study for $\mathrm{R} 1336 \mathrm{mzz}(\mathrm{Z})$ at three different saturation temperatures: $277.6 \mathrm{~K}, 298.1 \mathrm{~K}$, and $318.1 \mathrm{~K}$. Comparison of the mean boiling curves shows that the heat transfer performance of $\mathrm{R} 1336 \mathrm{mzz}(\mathrm{Z})$ at the intermediate temperature $(298.1 \mathrm{~K})$ exceeds those for the measurements taken for the higher and the lower saturation temperatures (for $\Delta T_{\mathrm{s}}>0.6 \mathrm{~K}$ ). In other words, the boiling heat transfer exhibits a maximum at a saturation temperature near $298.1 \mathrm{~K}$ with the $\mathrm{R} 1336 \mathrm{mzz}(\mathrm{Z})$ boiling curves for the two 
higher saturation temperatures $(318.1 \mathrm{~K}$ and $298.1 \mathrm{~K})$ exhibiting better performance than that for the lowest saturation temperature of $277.6 \mathrm{~K}$.

For more detail, Fig. 7 plots the ratio of the heat fluxes for R1336mzz(Z) at saturation temperatures of $318.1 \mathrm{~K}$ and $298.1 \mathrm{~K}$ relative to the $\mathrm{R} 1336 \mathrm{mzz}(\mathrm{Z})$ heat flux for $277.6 \mathrm{~K}$ at the same wall superheat. The heat flux ratios are plotted against the heat flux for $\mathrm{R} 1336 \mathrm{mzz}(\mathrm{Z})$ at the $277.6 \mathrm{~K}$ saturation condition. As done for Fig. 5, the heat flux ratio is shown as a solid line with dashed lines and shaded regions representing the $95 \%$ multi-use confidence level for each mean. For both heat flux ratio plots, the largest heat flux ratio occurred at the lowest heat flux, while the smallest heat flux ratio was seen for the highest heat fluxes. The heat flux ratio lines are roughly parallel having heat flux ratios of $1.88 \pm 0.025$ and $1.45 \pm 0.035$ at approximately $23 \mathrm{kWm}^{-2}$ for the $298.1 \mathrm{~K}$ and the $318.1 \mathrm{~K}$ saturation temperatures, respectively. The average heat flux ratio for heat fluxes less than 23 $\mathrm{kWm}^{-2}$ was approximately 2.35 and 1.86 for the $298.1 \mathrm{~K}$ and the $318.1 \mathrm{~K}$ saturated conditions, respectively. The average heat flux ratio for heat fluxes larger than $23 \mathrm{kWm}^{-2}$ was approximately 1.43 and 1.16 for the $298.1 \mathrm{~K}$ and the $318.1 \mathrm{~K}$ saturated conditions, respectively. For heat fluxes between $10 \mathrm{kWm}^{-2}$ and $84 \mathrm{kWm}^{-2}$, the average heat flux ratios were approximately 1.55 and 1.25 for the $\mathrm{R} 1336 \mathrm{mzz}(\mathrm{Z})$ saturation temperatures of $298.1 \mathrm{~K}$ and $318.1 \mathrm{~K}$, respectively.

\section{POOL BOILING MODEL}

The following describes an improvement to the pool boiling model for the Turbo-ESP surface that was developed in Kedzierski et al. (2018). The improvement was mainly achieved by including the present boiling measurements along with the Kedzierski et al. (2018) measurements to expand the validity of the model. The original model includes an adjustment for refrigerant mixtures that is not modified here because it a multiplicative correction factor that is expected to remain valid.

\section{$\underline{\text { Single Component }}$}

As outlined in Kedzierski et al. (2018), the total boiling heat flux is modeled as a sum of the boiling phase-change heat flux $\left(q_{\mathrm{b}}^{\prime}\right)$ and the heat flux due to single phase convection $\left(q_{\mathrm{c}}{ }^{\prime}\right)$ :

$$
q^{\prime \prime}=q_{\mathrm{b}}^{\prime \prime}+q_{\mathrm{c}}^{\prime \prime}=n_{\mathrm{b}}\left(h_{\mathrm{fg}} \rho_{\mathrm{v}} V_{\mathrm{b}}+\rho_{\mathrm{l}} c_{\mathrm{pl}} V_{\mathrm{bL}} \Delta T_{\mathrm{s}}\right)
$$

where $n_{\mathrm{b}}$ is the number of bubbles generated per unit time and per unit area. In addition, the properties of the refrigerant are the latent heat of vaporization $\left(h_{\mathrm{fg}}\right)$, the vapor density $\left(\rho_{\mathrm{v}}\right)$, the liquid density $\left(\rho_{1}\right)$, and the liquid specific heat $\left(c_{\mathrm{pl}}\right)$. The average volume of a single bubble is $V_{\mathrm{b}}$ and the volume of superheated liquid that a single bubble carries away with it

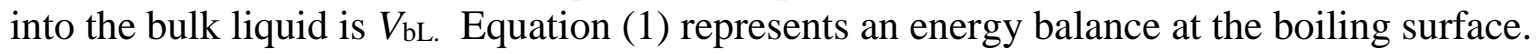
Although the second term represents heat leaving as single phase, the superheated liquid associated with it evaporates into the bubble immediately after being formed. This concept is consistent with that proposed by Mikic and Rohsenow (1969). 
The volume of superheated liquid that is carried away from a single bubble is approximated by the product of the bubble surface area and the thickness of the superheated layer $(I)$ that uniformly surrounds the entire bubble surface as:

$$
V_{\mathrm{bL}}=\pi D_{\mathrm{b}}^{2} \Gamma=4.84 V_{\mathrm{b}}^{2 / 3} \Gamma
$$

The Fritz (1935) expression for the bubble diameter $\left(D_{\mathrm{b}}\right)$ is used to obtain a relation for the volume of a single bubble as:

$$
V_{\mathrm{b}}=\frac{\pi}{6} D_{\mathrm{b}}^{3}=\frac{\pi}{6}(0.0208 \theta)^{3}\left(\frac{\sigma}{g\left(\rho_{1}-\rho_{\mathrm{v}}\right)}\right)^{3 / 2}=c_{0}\left(\frac{\sigma}{g\left(\rho_{1}-\rho_{\mathrm{v}}\right)}\right)^{3 / 2}
$$

The constant $c_{0}$ will be approximately equal to 0.2 considering that a typical value for the contact angle $(\theta)$ of a refrigerant is $35^{\circ}$ (Kedzierski, 1993). The Kedzierski et al. (2018) model omitted the gravitational acceleration constant $(g)$ in eq. (3), which was incorporated into another constant. It is included here so that the bubble volume has the correct units of cubic meters.

Mikic and Rohsenow (1969) showed that the bubble site density is proportional to the wall superheat raised to some power. The $n_{\mathrm{b}}$ can be obtained from a product of the bubble site density and the bubble frequency. Kedzierski (1995) showed that the bubble frequency can be widely variant due to interaction with adjacent sites, but in general, increases with heat flux and wall superheat. Considering the difficulty in modeling the bubble frequency, its functionality with respect to superheat is lumped with that of the active site density in a way that the relationship for $n_{\mathrm{b}}$ is assumed to be:

$$
n_{\mathrm{b}}=c_{1} \Delta T_{\mathrm{s}}^{\mathrm{m}}
$$

where $c_{1}$ is a constant while the exponent $\mathrm{m}$ is proposed here to be a function of the probability of a site being active, which is assumed to be directly related to the ratio of the thermal boundary layer thickness $(\delta)$ on the boiling surface and the bubble diameter $\left(D_{\mathrm{b}}\right)$ :

$$
\mathrm{m}=\frac{\delta}{D_{\mathrm{b}}}=\beta \sqrt{\frac{\mu_{1} g\left(\rho_{1}-\rho_{\mathrm{v}}\right)}{c_{\mathrm{pl}} \sigma}}
$$

Equation (5) was derived in Kedzierski et al. (2018) 5 by using the approximation for the pool boiling thermal boundary layer thickness proportionality as the square-root of the ratio of the liquid viscosity to the liquid specific heat $\left(\sqrt{\mu_{1} / c_{\mathrm{p} 1}}\right)$ from Kedzierski (2007) and the bubble

\footnotetext{
5 The expression for $\mathrm{m}$ that was derived in Kedzierski et al. (2018) incorporated the gravitational acceleration as part of $c_{1}$.
} 
diameter from Fritz (1935) with all the non-property parameters combined into a single constant $\beta$. Larger active site densities occur for thicker boundary layers (Hsu, 1962) and for smaller bubbles because the bubbles are less likely to grow beyond the boundary layer and recondense. A larger value for $m$ represents a greater probability that more sites will be active, which will be reflected in a larger value for $n_{\mathrm{b}}$.

Substitution of eqs. (2) through (5) into eq. (1) yields:

$$
q^{\prime \prime}=c_{1} \Delta T_{\mathrm{s}} \sqrt{\frac{\mu_{1} g\left(\rho_{1}-\rho_{\mathrm{v}}\right)}{c_{\mathrm{pl}} \cdot \sigma}}\left\lceil h_{\mathrm{fg}} \rho_{\mathrm{v}} c_{0}\left\{\frac{\sigma}{g\left(\rho_{1}-\rho_{\mathrm{v}}\right)}\right)^{3 / 2}+\rho_{1} c_{\mathrm{pl}} 4.84 c_{0}^{2 / 3}\left\{\frac{\sigma}{g\left(\rho_{1}-\rho_{\mathrm{v}}\right)}\right) \Gamma \Delta T_{\mathrm{s}}\right\}
$$

An expression for the thickness of the superheated layer on the bubble can be derived by starting with the Stokes (1880) expression for the terminal velocity of a bubble rising through a liquid due to buoyance:

$$
u=\frac{\rho\left(\rho_{1}-\rho_{\mathrm{v}}\right) g D_{\mathrm{b}}^{3}}{18 \mu_{1}^{2}}
$$

While using the Fritz (1935) equation for the bubble diameter, the Reynolds number (Re) based on the Stokes (1880) velocity is:

$$
\mathrm{Re}=\frac{\rho_{1} u D_{\mathrm{b}}}{\mu_{1}}=\frac{c_{0} \rho_{1} \sigma}{3 \pi \mu_{1}^{2}} \sqrt{\frac{\sigma}{\left(\rho_{1}-\rho_{\mathrm{v}}\right) g}}=\frac{0.0214 \rho_{1} \sigma}{\mu_{1}^{2}} \sqrt{\frac{\sigma}{\left(\rho_{1}-\rho_{\mathrm{v}}\right) g}}
$$

Simple dimensionless analysis yields a non-dimensional superheat layer thickness for the bubble as $\Gamma \rho \mathrm{l} \sigma / \mu^{2}$, which was regressed to the bubble Reynolds number as:

$$
\frac{\Gamma \rho_{1} \sigma}{\mu_{1}^{2}}=0.17 \mathrm{Re}^{1.39}
$$

Solving eq. (9) for $\Gamma$ and substituting it into eq. (6) and grouping constants gives the complete boiling model for the Turbo-EPS surface:

$$
q^{\prime \prime}=\Psi \cdot \Delta T_{\mathrm{s}} \sqrt{\frac{\mu_{\mathrm{g} g\left(\rho_{1}-\rho_{\mathrm{v}}\right)}}{c_{\mathrm{p} 1} \cdot \sigma}}\left\{h_{\mathrm{fg}} \rho_{\mathrm{v}}\left\{\frac{\sigma}{g\left(\rho_{1}-\rho_{\mathrm{v}}\right)}\right)^{3 / 2}+\frac{\Phi \mu_{1}^{2} c_{\mathrm{p} 1} \mathrm{Re}^{1.39}}{g\left(\rho_{1}-\rho_{\mathrm{v}}\right)} \Delta T_{\mathrm{s}}\right\}
$$

Regression of the boiling measurements presented here along with those for the single component fluids given in Kedzierski et al. (2018) resulted in values of the three regression 
constants as: $\beta=1.17 \mathrm{~kg}^{1 / 2} \mathrm{~s}^{1 / 2} \mathrm{~K}^{1 / 2} \mathrm{~m}^{-5 / 2}, \Psi=1.05 \times 10^{7} \mathrm{~m}^{-2} \mathrm{~s}^{-1}, \Phi=1.4$. Because only two fluids were regressed in the Kedzierski (2018) study, the term with the $\Phi$ constant was shown to be not statistically significant. The present regression with six fluids yielded a statistically significant, "convection" term which shows that heat transfer by bubbles lifting superheat from the wall is significant. Given that eq. (4) is dimensional, the $\Delta T_{\mathrm{s}}$ must be in units of kelvin when used in eq. (10). Future work is required to generate $\beta, \Psi$, and $\Phi$ for other boiling surfaces.

Figures 8 and 9 compare eq. (10) to the pool boiling measurements for R123 and R1336mzz(Z) of the present study and R134a and R1234yf from Kedzierski et al. (2018). On average, the model predicts the six fluids within $\pm 10 \%$. Figure 8 shows that the worst predictions are for $\mathrm{R} 1336 \mathrm{mzz}(\mathrm{Z})$ at $298.1 \mathrm{~K}$ where the model underpredicts the measured heat flux, on average, by approximately $25 \%$. The reason that the model poorly predicts the boiling performance of $\mathrm{R} 1336 \mathrm{mzz}(\mathrm{Z})$ at $298.1 \mathrm{~K}$ is that it does not account for the mechanism that causes the maximum heat flux observed for this fluid with respect to saturation temperature. The cause of the maximum is not understood; therefore, it cannot be presently modeled. Figure 9 shows that the best predictions are for R1234yf where the model over predicts the measured heat flux, on average, by approximately $3 \%$. On average, the model predicts the boiling heat flux for R123, R134a, R1336mzz(Z) at $277.6 \mathrm{~K}$, and at $318.1 \mathrm{~K}$ within $11 \%, 8 \%, 9 \%$, and $5 \%$, respectively. In addition, the superheat is predicted to within $\pm 0.5 \mathrm{~K}$ for all of the fluids.

\section{FUTURE WORK}

More boiling measurements are required to verify the generalization of the model for all refrigerants and to predict the maximum in boiling with respect to saturation temperature. High speed videos of the boiling phenomena, including the bubble departure diameter, the bubble departure frequency, the bubble velocity, the number of active sites, and the contact angle, would assist in developing an understanding of the influence of these parameters on the boiling characteristics. Because the model is built with these parameters or the parameters can be incorporated more directly in the model, the behavior of each parameter can be compared to the model components (e.g. eqs. (4) and (7)) so that they can be either verified or improved. The above work is of value because a robust pool boiling model is essential for the evaluation of the performance of new low-GWP refrigerants.

\section{CONCLUSIONS}

The pool boiling performance of a R123 and R1336mzz(Z) on a flattened, horizontal TurboESP surface was investigated. The study showed that the boiling performance of R123 and R1336mzz(Z) on the Turbo-ESP exhibited no discernable difference for most test heat fluxes at a saturation test temperature of $277.6 \mathrm{~K}$. R1336mzz(Z) was tested at two higher saturation temperatures and showed that the best performance was for the intermediate test temperature of $298.1 \mathrm{~K}$.

A previously developed model was improved to predict the single-component pool boiling of the test refrigerants on the Turbo-ESP surface. The improvement in the model consisted of the introduction of a single-phase heat transfer term. The model accounts for viscosity effects on bubble population and uses the Fritz (1935) equation to account for increased vapor production with increasing superheat. The previously developed model for multi- 
component pool boiling is recommended to be used with the present model. For most heat fluxes, the model predicted the measured superheat to within $\pm 0.5 \mathrm{~K}$.

\section{ACKNOWLEDGEMENTS}

This work was funded by the National Institute of Standards and Technology (NIST). Thanks go to D. Han of Ingersoll Rand and to the following NIST personnel for their constructive criticism of the draft manuscript: B. Dougherty and P. Domanski. Furthermore, the author extends appreciation to A. Heckert of the NIST Statistical Engineering Division for his consultations on the uncertainty analysis. In-kind donations of the test refrigerants by K. Kontomaris of Chemours are greatly appreciated. 


\section{NOMENCLATURE}

English Symbols

$A_{\mathrm{n}} \quad$ regression constant in Table $4 \mathrm{n}=0,1,2,3$

$B_{\mathrm{n}} \quad$ regression constants in eq. (8) $\mathrm{n}=0,1$

$c_{\mathrm{n}} \quad$ regression constants in eqs. (3) and (4) $\mathrm{n}=0,1$

$c_{\mathrm{pl}} \quad$ specific heat of liquid, $\mathrm{J} \mathrm{kg}^{-1} \mathrm{~K}^{-1}$

$D_{\mathrm{b}} \quad$ bubble diameter, $\mathrm{m}$

$g$ gravitational acceleration constant, $9.8 \mathrm{~m} \mathrm{~s}^{-2}$

$h_{\mathrm{fg}} \quad$ latent heat of vaporization, $\mathrm{J} \mathrm{kg}^{-1}$

$k \quad$ thermal conductivity, $\mathrm{W} \cdot \mathrm{m}^{-1} \cdot \mathrm{K}^{-1}$

$L \quad$ test surface length shown in Fig. 3, m

$\mathrm{m} \quad$ exponent term in eq. (4) and defined in eq. (5)

$n$ b number of bubbles per unit time per unit area, $\mathrm{s}^{-1} \mathrm{~m}^{-2}$

$P \quad$ pressure, $\mathrm{Pa}$

$q^{\prime \prime} \quad$ average wall heat flux based on projected area, $\mathrm{W} \cdot \mathrm{m}^{-2}$

$T$ temperature, $\mathrm{K}$

$u \quad$ velocity, $\mathrm{m} \cdot \mathrm{s}^{-1}$

$U \quad$ expanded uncertainty

$V \quad$ volume, $\mathrm{m}^{3}$

$X \quad$ model terms given in Table 1

\section{Greek symbols}

$\beta \quad$ dimensional constant in eq. (5), $1.17 \mathrm{~kg}^{1 / 2} \mathrm{~s}^{1 / 2} \mathrm{~K}^{1 / 2} \mathrm{~m}^{-5 / 2}$

$\Gamma \quad$ thickness of superheated layer on bubble, $\mathrm{m}$

$\delta \quad$ thermal boundary layer thickness, $\mathrm{m}$

$\Delta T_{\mathrm{g}} \quad$ temperature glide: $T_{\mathrm{d}}-T_{\mathrm{b}}, \mathrm{K}$

$\Delta T_{\mathrm{s}} \quad$ wall superheat: $T_{\mathrm{w}}-T_{\mathrm{s}}, \mathrm{K}$

$\theta \quad$ contact angle, degrees

$\mu \quad$ dynamic viscosity, $\mathrm{kg} \cdot \mathrm{m}^{-1} \cdot \mathrm{s}^{-1}$

$\sigma \quad$ surface tension of refrigerant, $\mathrm{N} \cdot \mathrm{m}^{-1}$

$\rho$ density, $\mathrm{kg} \cdot \mathrm{m}^{-3}$

$\Phi \quad$ non-dimensional constant in eq. (10), 1.4

$\Psi \quad$ dimensional constant in eq. (10), $1.05 \times 10^{7} \mathrm{~m}^{-2} \mathrm{~s}^{-1}$

\section{English Subscripts}

$\mathrm{d}$ diffusion or dew point

b bubble or bubble point

bL bubble layer

c convection

g glide

1 liquid refrigerant

m mixture

q" heat flux

s saturated state, streaming

w wall temperature

$\mathrm{v}$ refrigerant vapor 


\section{REFERENCES}

ASHRAE. 2016. Designation and Safety Classification of Refrigerants, ANSI/ASHRAE Standard 34-2016.

Belsley, D. A., Kuh, E., and Welsch, R. E. 1980. Regression Diagnostics: Identifying Influential Data and Sources of Collinearity, New York: Wiley.

Donaldson, B., Nagengast, B., and Meckler, G. 1995. Heat and Cold: Mastering the Great Indoors: A Selective History, ASHRAE, New York, p. 261.

EU. 2014. Regulation (Eu) No 517/2014 of the European Parliament and of the Council of 16 April 2014 on fluorinated greenhouse gases and repealing Regulation (EC) No 842/2006, Official Journal of the European Union, L 150/195, http://data.europa.eu/eli/reg/2014/517/oj.

Fritz, W. 1935. Berechnung des Maximalvolume von Dampfblasen, Physikalische Zeitschrift, 36, 379-388.

Gorgy, E. 2016. Nucleate boiling of low-GWP refrigerants on highly enhanced tube surface, Int. J. Heat Mass Transfer, 96, 660-6.

Gorgy, E, and Eckels, S. 2012. Local heat transfer coefficient for pool boiling of R-134a and R-123 on smooth and enhanced tubes. Int. J. Heat Mass Transfer, 55, 3021-8.

Gorgy, E., and Eckels, S. 2010. Average Heat Transfer Coefficient for Pool Boiling of R134a and R-123 on Smooth and Enhanced Tubes (RP-1316). HVAC\&R Res, 16, 657-76.

Hsu, Y. Y. 1962. On the Size Range of Active Nucleation Cavities on a Heating Surface, J. Heat Transfer, 84, 207-216.

Kedzierski, M. A., Lin, L., and, Kang, D. Y. 2018. Pool Boiling of Low GWP Replacements for R134a on a Reentrant Cavity Surface, J. Heat Transfer, 140(12), doi:10.1115/1.4040783.

Kedzierski, M. A. 2007. Effect of Refrigerant Oil Additive on R134a and R123 Boiling Heat Transfer Performance, Int. J. Refrigeration, 30(1), 144-154.

Kedzierski, M. A. 2002. Use of Fluorescence to Measure the Lubricant Excess Surface Density During Pool Boiling, Int. J. Refrigeration, 25, 1110-1122.

Kedzierski, M. A. 2001. Use of Fluorescence to Measure the Lubricant Excess Surface Density During Pool Boiling, NISTIR 6727, U.S. Department of Commerce, Washington, D.C.

Kedzierski, M. A. 1999. Ralph L. Webb: A Pioneering Proselytizer for Enhanced Heat Transfer, J. Enhanced Heat Transfer, 6(2-4), 71-78. 
Kedzierski, M. A. 1995. Calorimetric and Visual Measurements of R123 Pool Boiling on Four Enhanced Surfaces, NISTIR 5732, U.S. Department of Commerce, Washington.

Kedzierski, M. A. 1993. Simultaneous Visual and Calorimetric Measurements of R11, R123, and R123/Alkylbenzene Nucleate Flow Boiling, Heat Transfer with Alternative Refrigerants, HTD-Vol. 243, H.J. Sauer, Jr., and T.H. Kuehn, Eds., ASME, New York, pp. 27-33.

Kontomaris, K. 2014a. HFO-1336mzz(Z): High temperature chemical stability and use as a working fluid in organic Rankine cycles. 15th International Refrigeration and Air Conditioning Conference at Purdue, West Lafayette, IN, USA, July 14-17.

Kontomaris, K. 2014b. Zero-ODP, low-GWP working fluids for high temperature heat pumps, ASHRAE Annual Conference, Seattle, Washington, June 28-July 2, 2014.

Kontomaris, K. 2013. A Low GWP Working Fluid for High Temperature Heat Pumps: DR2, European Heat Pump Summit, Nuremberg, Germany, Oct. 15-16.

Kontomaris, K. 2011. Processes and compositions for organic Rankine cycles for generating mechanical energy from heat, Patent Appl. PCT/US2012/051239, Pub. No. WO/2013/028476 A2, Pub. Date Feb 28, 2013, Inter. Filing Date Aug 16, 2012, Priority No.

US2011/61/525,531P, Priority date Aug 19, 2011.

Kontomaris, K. 2010. A Low GWP Replacement for HCFC-123 in Centrifugal Chillers: DR2, ASHRAE \& UNEP Conference "Road to Climate Friendly Chillers: Moving Beyond CFCs and HCFCs", Cairo, Egypt, Sep. 30th - Oct. 1st.

Lee, Y., Kang, D. G., Kim, J. H., Jung, D. 2014. Nucleate boiling heat transfer coefficients of HFO1234yf on various enhanced surfaces. Int. J. Refrigeration, 38, 198-205.

Lemmon, E. W., Bell, I. H., Huber, M. L., and McLinden, M. O. 2018. NIST Standard Reference Database 23 (REFPROP), Version 10., National Institute of Standards and Technology, Boulder, CO.

Locke, A., A. 1930. Integral Finned Tubing and Method of Manufacturing the Same, US Patent 1,761,733.

Loh, G., K. Kontomaris, S. A. Ata, and Grover, V. K. 2014. Formacel® 1100 - a HFO with unique characteristics for polyurethane foam applications, Polyurethane Technical Conference, Dallas, Texas, Sep. 22-24.

Mikic, B., B, and Rohsenow, W. M. 1969. A New Correlation of Pool-Boiling Data Including the Effect of Heating Surface Characteristics, J. Heat Transfer, 91(2), 245-250.

Moreno, G., Narumanchi, S., King, C. 2013. Pool Boiling Heat Transfer Characteristics of HFO-1234yf on Plain and Microporous-Enhanced Surfaces, J. Heat Transfer, 135, 111014. 
Montreal Protocol 1987. Montreal Protocol on Substances that Deplete the Ozone Layer. United Nations (UN), New York, NY, USA (1987 with subsequent amendments).

Myhre, G., D. Shindell, F.-M. Bréon, W. Collins, J. Fuglestvedt, J. Huang, D. Koch, J.-F. Lamarque, D. Lee, B. Mendoza, T. Nakajima, A. Robock, G. Stephens, T. Takemura and H. Zhang. 2013. Anthropogenic and Natural Radiative Forcing Supplementary Material. In: Climate Change 2013: The Physical Science Basis. Contribution of Working Group I to the Fifth Assessment Report of the Intergovernmental Panel on Climate Change [Stocker, T.F., D. Qin, G.-K. Plattner, M. Tignor, S.K. Allen, J. Boschung, A. Nauels, Y. Xia, V. Bex and P.M. Midgley (eds.)]. Available from www.climatechange2013.org and www.ipcc.ch.

Park, K. J., Jung, D. 2010. Nucleate boiling heat transfer coefficients of R1234yf on plain and low fin surfaces. Int. J. Refrigeration, 33, 553-7.

Rogers, J. S. 1961. Study of Low-Fin Tube 1929-1960, Wolverine Tube, Inc, Internal Report Neshan-1, p. 8.

Schluender, E. U. 1983. Heat transfer in nucleate boiling of mixtures. Int. Chemical Engineering, 23(4), 589-599.

Shock, R. A. W. 1982. Boiling in Multicomponent Fluids, Multiphase Science and Technology, Hemisphere Publishing Corp, 1, 281-386.

Stokes, G. G. 1880. Mathematical and Physical Papers, 1, Cambridge University Press, London, 1880

UNEP, 2016. Amendment to the Montreal Protocol on Substances that Deplete the Ozone Layer, Kigali, 15 October 2016. https://treaties.un.org/doc/Publication/CN/2016/ CN.872.2016-Eng.pdf (accessed July 25, 2017).

Webb, R. L. 1972. Heat Transfer Surface Having a High Boiling Heat Transfer Coefficient, US patent 3,696,861.

Wilson, E.E. 1915. A Basis for Rational Design of Heat Transfer Apparatus, Trans. ASME, 37, 47-70.

World Meteorological Organiza-tion (WMO). 2006. Scientific Assessment of Ozone Depletion, WMO, Geneva, Switzerland.

Wysong, E.B., Grover, V.K., Marchione, A.A., and Naicker, P. L. 2014. Formacel ${ }^{\mathrm{TM}} 1100$ : Spray Polyurethane Foam Application Development", Proceedings of Polyurethanes Technical Conference, Dallas, TX, USA. 
Table 1 Conduction model choice

\begin{tabular}{|c|c|}
\hline $\begin{array}{r}\mathrm{X}_{0}=\text { constant (all models) } \\
\mathrm{X}_{5}=\mathrm{y}\left(3 \mathrm{x}^{2}-\mathrm{y}^{2}\right) \quad \mathrm{X}\end{array}$ & $\begin{array}{l}1=x \\
x^{2}-y^{2} \\
\left.y^{2}-x^{2}\right) \quad X_{2}=y \quad X_{7}=x y \\
y^{3}-x y^{3}\end{array}$ \\
\hline Fluid $\left[T_{\mathrm{s}}\right]$ & Most frequent models \\
\hline $\begin{array}{c}\mathrm{R} 123[277.6 \mathrm{~K}] \\
0.7 \mathrm{~K} \leq \Delta T_{\mathrm{s}} \leq 2.7 \mathrm{~K}\end{array}$ & $\begin{array}{c}\mathrm{X}_{1}, \mathrm{X}_{3}(161 \text { of } 189) 61 \% \\
\mathrm{X}_{1}, \mathrm{X}_{3}, \mathrm{X}_{7}(68 \text { of } 189) 36 \% \\
\mathrm{X}_{1}, \mathrm{X}_{2}, \mathrm{X}_{5}(6 \text { of } 189) 3 \%\end{array}$ \\
\hline $\begin{array}{c}\mathrm{R} 1336 \mathrm{mmz}(\mathrm{Z})[277.6 \mathrm{~K}] \\
0.9 \mathrm{~K} \leq \Delta T_{\mathrm{s}} \leq 2.9 \mathrm{~K}\end{array}$ & $\begin{array}{c}\mathrm{X}_{1}, \mathrm{X}_{3}(178 \text { of } 378) 47 \% \\
\mathrm{X}_{1}, \mathrm{X}_{3}, \mathrm{X}_{7}(154 \text { of } 378) 41 \% \\
\mathrm{X}_{1}, \mathrm{X}_{2}, \mathrm{X}_{5}(13 \text { of } 378) 3 \% \\
\mathrm{X}_{1}, \mathrm{X}_{2}, \mathrm{X}_{5}, \mathrm{X}_{7}(10 \text { of } 378) 5 \%\end{array}$ \\
\hline $\begin{array}{c}\mathrm{R} 1336 \mathrm{mmz}(\mathrm{Z})[298.1 \mathrm{~K}] \\
0.5 \mathrm{~K} \leq \Delta T_{\mathrm{s}} \leq 2.5 \mathrm{~K}\end{array}$ & $\begin{array}{c}\mathrm{X}_{1}, \mathrm{X}_{2}, \mathrm{X}_{5}(77 \text { of } 158) 49 \% \\
\mathrm{X}_{1}, \mathrm{X}_{2}, \mathrm{X}_{5}, \mathrm{X}_{7}(25 \text { of } 158) 16 \% \\
\mathrm{X}_{1}, \mathrm{X}_{3}, \mathrm{X}_{5}(23 \text { of } 158) 15 \% \\
\mathrm{X}_{1}, \mathrm{X}_{3}, \mathrm{X}_{5}, \mathrm{X}_{7}(18 \text { of } 158) 12 \%\end{array}$ \\
\hline $\begin{array}{c}\mathrm{R} 1336 \mathrm{mmz}(\mathrm{Z})[318.1 \mathrm{~K}] \\
0.6 \mathrm{~K} \leq \Delta T_{\mathrm{s}} \leq 3.0 \mathrm{~K}\end{array}$ & $\begin{array}{c}\mathrm{X}_{1}, \mathrm{X}_{2}, \mathrm{X}_{5}(127 \text { of } 162) 76 \% \\
\mathrm{X}_{1}, \mathrm{X}_{2}(20 \text { of } 162) 13 \% \\
\mathrm{X}_{1}, \mathrm{X}_{5}(11 \text { of } 162) 7 \%\end{array}$ \\
\hline
\end{tabular}


Table 2 Pool boiling data

R123, $T_{\mathrm{s}}=277.6 \mathrm{~K}$

\begin{tabular}{|c|c|}
\hline $\begin{array}{l}\Delta T_{\mathrm{s}} \\
(\mathrm{K})\end{array}$ & $\begin{array}{c}q^{\prime \prime} \\
\left(\mathrm{Wm}^{-2}\right)\end{array}$ \\
\hline 2.74 & 94982. \\
\hline 2.74 & 95041. \\
\hline 2.55 & 88266. \\
\hline 2.55 & 88289. \\
\hline 2.39 & 81116. \\
\hline 2.39 & 81117. \\
\hline 2.23 & 73941. \\
\hline 2.22 & 73874. \\
\hline 2.06 & 66856. \\
\hline 2.06 & 66945. \\
\hline 1.92 & 60066. \\
\hline 1.90 & 60057. \\
\hline 1.77 & 52989. \\
\hline 1.76 & 52947. \\
\hline 1.60 & 46143. \\
\hline 1.60 & 46217. \\
\hline 1.47 & 39567. \\
\hline 1.47 & 39506. \\
\hline 1.36 & 32694. \\
\hline 1.34 & 32718. \\
\hline 1.21 & 26493. \\
\hline 1.22 & 26524. \\
\hline 1.08 & 20203. \\
\hline 1.06 & 20211. \\
\hline 0.92 & 14312. \\
\hline 0.89 & 14358. \\
\hline 0.73 & 9193. \\
\hline 2.71 & 95652. \\
\hline 2.69 & 95593. \\
\hline 2.55 & 88617. \\
\hline 2.53 & 88676. \\
\hline 2.36 & 81390. \\
\hline 2.37 & 81300. \\
\hline 2.19 & 74265 . \\
\hline 2.19 & 74298. \\
\hline 2.01 & 66924. \\
\hline 2.01 & 66860. \\
\hline 1.87 & 59884. \\
\hline 1.88 & 60252. \\
\hline 1.72 & 53371. \\
\hline 1.72 & 53432. \\
\hline 1.59 & 46642. \\
\hline 1.57 & 46647. \\
\hline 1.44 & 39352. \\
\hline 1.45 & 39359. \\
\hline 1.30 & 32789. \\
\hline 1.31 & 32754. \\
\hline 1.20 & 25729. \\
\hline 1.21 & 25707. \\
\hline 1.04 & 19860. \\
\hline 1.03 & 19856. \\
\hline 0.88 & 14153. \\
\hline 0.88 & 14087. \\
\hline 0.70 & 9598. \\
\hline 2.70 & 95217. \\
\hline 2.68 & 95300. \\
\hline 2.53 & 88500. \\
\hline 2.53 & 88415. \\
\hline
\end{tabular}

\begin{tabular}{|l|l|}
\hline 2.36 & 81498. \\
\hline 2.36 & 81469. \\
\hline 2.20 & 74182. \\
\hline 2.18 & 74150. \\
\hline 2.03 & 67265. \\
\hline 2.01 & 67195. \\
\hline 1.87 & 60119. \\
\hline 1.88 & 60147. \\
\hline 1.73 & 53352. \\
\hline 1.72 & 53449. \\
\hline 1.58 & 45988. \\
\hline 1.58 & 45996. \\
\hline 1.45 & 39316. \\
\hline 1.44 & 39357. \\
\hline 1.33 & 32727. \\
\hline 1.32 & 32773. \\
\hline 1.20 & 26361. \\
\hline 1.21 & 26332. \\
\hline 1.09 & 19123. \\
\hline 1.08 & 19109. \\
\hline 0.90 & 13964. \\
\hline 0.89 & 14007. \\
\hline 0.66 & 9515. \\
\hline 2.79 & 95513. \\
\hline 2.78 & 95539. \\
\hline 2.60 & 88271. \\
\hline 2.61 & 88306. \\
\hline 2.41 & 81572. \\
\hline 2.42 & 81599. \\
\hline 2.27 & 74331. \\
\hline 2.28 & 74388. \\
\hline 2.14 & 67051. \\
\hline 2.12 & 67112. \\
\hline 1.96 & 60521. \\
\hline 1.97 & 60573. \\
\hline 1.82 & 53418. \\
\hline 1.82 & 53380. \\
\hline 1.66 & 46534. \\
\hline 1.65 & 46567. \\
\hline 1.51 & 39529. \\
\hline 1.50 & 39510. \\
\hline 1.35 & 32943. \\
\hline 1.35 & 32892. \\
\hline 1.27 & 25741. \\
\hline 1.25 & 25657. \\
\hline 1.06 & 19896. \\
\hline 1.06 & 19913. \\
\hline 0.89 & 14589. \\
\hline 0.88 & 14522. \\
\hline 0.72 & 9325. \\
\hline 2.70 & 94878. \\
\hline 2.70 & 94891. \\
\hline 2.52 & 88440. \\
\hline 2.51 & 88476. \\
\hline 2.35 & 81479. \\
\hline 2.35 & 81407. \\
\hline 2.19 & 74385. \\
\hline 2.17 & 74411. \\
\hline 2.04 & 67198. \\
\hline 2.02 & 67256. \\
\hline 1.90 & 60536. \\
\hline 1.90 & 60537. \\
\hline & \\
\hline
\end{tabular}

\begin{tabular}{|l|l|}
\hline 1.78 & 54008. \\
\hline 1.76 & 53819. \\
\hline 1.67 & 46239. \\
\hline 1.66 & 46225. \\
\hline 1.51 & 39340. \\
\hline 1.50 & 39369. \\
\hline 1.39 & 32293. \\
\hline 1.38 & 32306. \\
\hline 1.24 & 25394. \\
\hline 1.24 & 25353. \\
\hline 1.07 & 19691. \\
\hline 1.06 & 19742. \\
\hline 0.89 & 14253. \\
\hline 0.88 & 14216. \\
\hline 0.69 & 9229. \\
\hline 2.64 & 96426. \\
\hline 2.64 & 96524. \\
\hline 2.49 & 88427. \\
\hline 2.48 & 88422. \\
\hline 2.29 & 8117. \\
\hline 2.29 & 81220. \\
\hline 2.09 & 74526. \\
\hline 2.10 & 74598. \\
\hline 1.94 & 67760. \\
\hline 1.95 & 67724. \\
\hline 1.88 & 60247. \\
\hline 1.87 & 60260. \\
\hline 1.70 & 53276. \\
\hline 1.69 & 53299. \\
\hline 1.55 & 47064. \\
\hline 1.54 & 47023. \\
\hline 1.44 & 40046. \\
\hline 1.45 & 40034. \\
\hline 1.33 & 32785. \\
\hline 1.34 & 32781. \\
\hline 1.20 & 25434. \\
\hline 1.19 & 25405. \\
\hline 1.03 & 19369. \\
\hline 1.02 & 19433. \\
\hline 0.89 & 14350. \\
\hline 0.89 & 14333. \\
\hline 0.69 & 9184. \\
\hline 2.66 & 95128. \\
\hline 2.62 & 95175. \\
\hline 2.44 & 88193. \\
\hline 2.46 & 88211. \\
\hline 2.26 & 81350. \\
\hline 2.25 & 81355. \\
\hline 2.12 & 74253. \\
\hline 2.10 & 74578. \\
\hline 1.98 & 67134. \\
\hline 1.95 & 67062. \\
\hline 1.80 & 60519. \\
\hline 1.81 & 60530. \\
\hline 1.69 & 53580. \\
\hline 1.67 & 53603. \\
\hline 1.59 & 46081. \\
\hline 1.58 & 46071. \\
\hline 1.42 & 39725. \\
\hline 1.42 & 39754. \\
\hline 1.31 & 33012. \\
\hline 1.30 & 32978. \\
\hline & \\
\hline
\end{tabular}




\begin{tabular}{|c|c|}
\hline 1.17 & 26684. \\
\hline 1.17 & 26645. \\
\hline 1.05 & 19860. \\
\hline 1.05 & 19835. \\
\hline 0.88 & 14430. \\
\hline 0.88 & 14358. \\
\hline 0.69 & 9487. \\
\hline 0.70 & 9462. \\
\hline
\end{tabular}

R1336mmz $(Z), T_{\mathrm{s}}=277.6 \mathrm{~K}$

\begin{tabular}{|c|c|}
\hline$\Delta T_{\mathrm{s}}$ & $q^{\prime \prime}$ \\
$(\mathrm{K})$ & $\left(\mathrm{Wm}^{-2}\right)$ \\
\hline 2.95 & 98997. \\
\hline 2.94 & 9905. \\
\hline
\end{tabular}

\begin{tabular}{|l|l|}
\hline 2.72 & 91728. \\
\hline 2.72 & 91626. \\
\hline 2.53 & 84222. \\
\hline
\end{tabular}

\begin{tabular}{|l|l|}
\hline 2.53 & 84222. \\
\hline 2.52 & 84260. \\
\hline
\end{tabular}

\begin{tabular}{|l|l|}
\hline 2.52 & 84260. \\
\hline 2.33 & 76533. \\
\hline 2.32 & 76434 \\
\hline
\end{tabular}

\begin{tabular}{|l|l|}
\hline 2.33 & 76533. \\
\hline 2.32 & 76434. \\
\hline 2.14 & 69149. \\
\hline 2.14 & 69099. \\
\hline
\end{tabular}

\begin{tabular}{|l|l|}
\hline 2.14 & 69149. \\
\hline 2.14 & 69099. \\
\hline 1.96 & 62148. \\
\hline
\end{tabular}

\begin{tabular}{|l|l|}
\hline 1.96 & 62148. \\
\hline 1.96 & 62160. \\
\hline 1.83 & 55484. \\
\hline 1.82 & 55474 \\
\hline
\end{tabular}

\begin{tabular}{|l|l|}
\hline 1.83 & 55484. \\
\hline 1.82 & 55474. \\
\hline 1.68 & 47853. \\
\hline 1.67 & 47863 \\
\hline
\end{tabular}

\begin{tabular}{|l|l|}
\hline 1.68 & 47853. \\
\hline 1.67 & 47863. \\
\hline 1.52 & 41236. \\
\hline
\end{tabular}

\begin{tabular}{|l|l|}
\hline 1.52 & 41236. \\
\hline 1.53 & 41177. \\
\hline 1.40 & 34401 \\
\hline
\end{tabular}

\begin{tabular}{|l|l|}
\hline 1.40 & 34401. \\
\hline 1.39 & 34392. \\
\hline 1.28 & 27702. \\
\hline
\end{tabular}

\begin{tabular}{|l|l|}
\hline 1.39 & 34392. \\
\hline 1.28 & 27702. \\
\hline 1.28 & 27634. \\
\hline
\end{tabular}

\begin{tabular}{|l|l|}
\hline 1.28 & 27634. \\
\hline 1.16 & 21361. \\
\hline 1.14 & 21356. \\
\hline 1.04 & 15086 \\
\hline
\end{tabular}

\begin{tabular}{|c|c|}
\hline 1.04 & 15086. \\
\hline 1.04 & 15022. \\
\hline 0.88 & 9461. \\
\hline 2.99 & 98241. \\
\hline
\end{tabular}

\begin{tabular}{|c|c|}
\hline 0.88 & 9461. \\
\hline 2.99 & 98241. \\
\hline 2.97 & 98261. \\
\hline 2.78 & 91025. \\
\hline
\end{tabular}

\begin{tabular}{|l|l|}
\hline 2.97 & 98261. \\
\hline 2.78 & 91025. \\
\hline 2.78 & 91045. \\
\hline 2.59 & 83922. \\
\hline
\end{tabular}

\begin{tabular}{|l|l|}
\hline 2.78 & 91045. \\
\hline 2.59 & 83922. \\
\hline 2.59 & 83891. \\
\hline
\end{tabular}

\begin{tabular}{|l|l|}
\hline 2.59 & 83891. \\
\hline 2.42 & 76163. \\
\hline 2.39 & 76153. \\
\hline
\end{tabular}

\begin{tabular}{|l|l|}
\hline 2.39 & 76153. \\
\hline 2.22 & 69338. \\
\hline 2.21 & 69427. \\
\hline
\end{tabular}

\begin{tabular}{|l|l|}
\hline 2.21 & 69427. \\
\hline 2.07 & 62902. \\
\hline 2.08 & 63094 \\
\hline
\end{tabular}

\begin{tabular}{|l|l|}
\hline 2.08 & 63094. \\
\hline 1.92 & 55782. \\
\hline 1.92 & 55893. \\
\hline
\end{tabular}

\begin{tabular}{|l|l|}
\hline 1.92 & 55893. \\
\hline 1.74 & 48493. \\
\hline 1.72 & 48542. \\
\hline
\end{tabular}

\begin{tabular}{|l|l|}
\hline 1.72 & 48542. \\
\hline 1.56 & 41629. \\
\hline 1.55 & 41554. \\
\hline
\end{tabular}

\begin{tabular}{|l|l|}
\hline 1.56 & 41629. \\
\hline 1.55 & 41554. \\
\hline 1.42 & 34186. \\
\hline
\end{tabular}

\begin{tabular}{|l|l|}
\hline 1.42 & 34186. \\
\hline 1.40 & 34232. \\
\hline 1.29 & 27113 \\
\hline
\end{tabular}

\begin{tabular}{|l|l|}
\hline 1.40 & 34232. \\
\hline 1.29 & 27113. \\
\hline 1.29 & 27135. \\
\hline 1.17 & 20851. \\
\hline 1.17 & 20820. \\
\hline 1.04 & 14833. \\
\hline
\end{tabular}

\begin{tabular}{|c|c|}
\hline 1.03 & 14799. \\
\hline 0.87 & 9086. \\
\hline 3.21 & 97400. \\
\hline 3.19 & 97443. \\
\hline 2.98 & 90373. \\
\hline 2.96 & 90357. \\
\hline 2.79 & 82768. \\
\hline 2.75 & 82730 . \\
\hline 2.53 & 75924. \\
\hline 2.53 & 75877. \\
\hline 2.36 & 69547. \\
\hline 2.34 & 69253. \\
\hline 2.19 & 62733. \\
\hline 2.18 & 62345. \\
\hline 1.98 & 55651. \\
\hline 1.99 & 55617. \\
\hline 1.80 & 48820. \\
\hline 1.80 & 48819. \\
\hline 1.62 & 41983. \\
\hline 1.60 & 41977. \\
\hline 1.45 & 34740. \\
\hline 1.44 & 34774. \\
\hline 1.31 & 27866. \\
\hline 1.31 & 27797. \\
\hline 1.19 & 21192. \\
\hline 1.20 & 21105. \\
\hline 1.04 & 15349. \\
\hline 1.04 & 15264. \\
\hline 0.85 & 10152. \\
\hline 3.00 & 95993. \\
\hline 3.00 & 95963. \\
\hline 2.79 & 88590. \\
\hline 2.77 & 88207. \\
\hline 2.55 & 81086. \\
\hline 2.55 & 81089. \\
\hline 2.34 & 74251. \\
\hline 2.34 & 74319. \\
\hline 2.22 & 67681. \\
\hline 2.21 & 67469. \\
\hline 2.08 & 61029. \\
\hline 2.08 & 61077. \\
\hline 1.92 & 54358. \\
\hline 1.91 & 54324. \\
\hline 1.75 & 48092. \\
\hline 1.75 & 48020. \\
\hline 1.60 & 41584. \\
\hline 1.59 & 41731. \\
\hline 1.43 & 34965. \\
\hline 1.42 & 34972. \\
\hline 1.35 & 28165. \\
\hline 1.34 & 28113. \\
\hline 1.20 & 21214. \\
\hline 1.20 & 21228. \\
\hline 1.05 & 15756. \\
\hline 1.04 & 15721. \\
\hline 0.91 & 9976. \\
\hline
\end{tabular}

\begin{tabular}{|c|c|}
\hline 3.00 & 98451. \\
\hline 2.99 & 98439. \\
\hline 2.79 & 91066. \\
\hline 2.79 & 90987. \\
\hline 2.59 & 84062. \\
\hline 2.58 & 84030. \\
\hline 2.42 & 77146. \\
\hline 2.42 & 77107. \\
\hline 2.23 & 69460. \\
\hline 2.21 & 69460. \\
\hline 2.05 & 62630. \\
\hline 2.05 & 62658. \\
\hline 1.87 & 55650. \\
\hline 1.87 & 55668. \\
\hline 1.71 & 48710. \\
\hline 1.70 & 48667. \\
\hline 1.55 & 41833. \\
\hline 1.55 & 41790. \\
\hline 1.41 & 34893. \\
\hline 1.41 & 34939. \\
\hline 1.26 & 28212. \\
\hline 1.27 & 28128. \\
\hline 1.13 & 21370. \\
\hline 1.13 & 21464. \\
\hline 1.01 & 15773. \\
\hline 1.00 & 15775. \\
\hline 0.88 & 10280. \\
\hline 2.93 & 99246. \\
\hline 2.94 & 99247. \\
\hline 2.74 & 92547. \\
\hline 2.73 & 92524. \\
\hline 2.54 & 85355. \\
\hline 2.53 & 85376. \\
\hline 2.30 & 77081. \\
\hline 2.30 & 76991. \\
\hline 2.11 & 70122. \\
\hline 2.10 & 70229. \\
\hline 1.96 & 63407. \\
\hline 1.94 & 63426. \\
\hline 1.77 & 56683. \\
\hline 1.77 & 56656. \\
\hline 1.62 & 49584. \\
\hline 1.62 & 49618. \\
\hline 1.45 & 42674. \\
\hline 1.45 & 42566. \\
\hline 1.31 & 35682. \\
\hline 1.31 & 35621. \\
\hline 1.16 & 28806. \\
\hline 1.16 & 28781. \\
\hline 1.05 & 21952. \\
\hline 1.05 & 21869. \\
\hline 0.94 & 15513. \\
\hline 0.93 & 15459. \\
\hline 0.79 & 10423. \\
\hline 2.86 & 99569. \\
\hline 2.85 & 99576. \\
\hline
\end{tabular}




\begin{tabular}{|c|c|}
\hline \multirow{2}{*}{$\frac{2.69}{2.68}$} & 92687. \\
\hline & 92796. \\
\hline 2.48 & 85688. \\
\hline 2.48 & 85698. \\
\hline 2.29 & 78340. \\
\hline 2.29 & 78308. \\
\hline 2.09 & 70413. \\
\hline 2.08 & 70524. \\
\hline 1.90 & 62740. \\
\hline 1.89 & 62754. \\
\hline 1.74 & 56616. \\
\hline 1.73 & 56301. \\
\hline 1.58 & 49801. \\
\hline 1.58 & 49795. \\
\hline 1.43 & 42710. \\
\hline 1.43 & 42676. \\
\hline 1.29 & 35442. \\
\hline 1.27 & 35456. \\
\hline 1.13 & 28239. \\
\hline 1.13 & 28202. \\
\hline 1.01 & 21576. \\
\hline 1.01 & 21593. \\
\hline 0.92 & 16042. \\
\hline 0.91 & 16021. \\
\hline 0.81 & 10159. \\
\hline 2.85 & 98566. \\
\hline 2.84 & 98607. \\
\hline 2.65 & 91668. \\
\hline 2.64 & 91727. \\
\hline 2.46 & 84801. \\
\hline 2.45 & 84756. \\
\hline 2.27 & 77693. \\
\hline 2.25 & 77867. \\
\hline 2.02 & 70359. \\
\hline 2.00 & 70430. \\
\hline 1.93 & 63437. \\
\hline 1.93 & 63446. \\
\hline 1.77 & 57042. \\
\hline 1.76 & 57160. \\
\hline 1.61 & 50351. \\
\hline 1.59 & 50347. \\
\hline 1.45 & 42926. \\
\hline 1.43 & 42995. \\
\hline 1.31 & 36052. \\
\hline 1.29 & 36170. \\
\hline 1.17 & 29225. \\
\hline 1.17 & 29136. \\
\hline 1.09 & 22196. \\
\hline 1.08 & 22190. \\
\hline 0.95 & 15991. \\
\hline 0.94 & 15999. \\
\hline 0.82 & 10552. \\
\hline 3.04 & 98613. \\
\hline 3.04 & 98580. \\
\hline 2.86 & 91259. \\
\hline 2.85 & 91246. \\
\hline 2.66 & 84195. \\
\hline 2.65 & 84071. \\
\hline 2.47 & 76801. \\
\hline 2.46 & 76734. \\
\hline 2.28 & 69513. \\
\hline 2.28 & 69528. \\
\hline 2.12 & 62360. \\
\hline 2.11 & 62366. \\
\hline 1.96 & 54946. \\
\hline
\end{tabular}

\begin{tabular}{|l|l|}
\hline 1.96 & 55326. \\
\hline 1.80 & 47566. \\
\hline 1.79 & 47594. \\
\hline 1.64 & 41189. \\
\hline 1.64 & 41098. \\
\hline 1.48 & 34443. \\
\hline 1.49 & 34376. \\
\hline 1.37 & 27651. \\
\hline 1.37 & 27590. \\
\hline 1.26 & 21355. \\
\hline 1.25 & 21279. \\
\hline 1.13 & 15015. \\
\hline 1.13 & 15010. \\
\hline 1.00 & 9233. \\
\hline 2.80 & 99382. \\
\hline 2.79 & 99369. \\
\hline 2.60 & 92418. \\
\hline 2.61 & 92486. \\
\hline 2.42 & 85229. \\
\hline 2.42 & 85265. \\
\hline 2.21 & 77506. \\
\hline 2.21 & 77510. \\
\hline 2.02 & 69850. \\
\hline 2.01 & 69866. \\
\hline 1.86 & 62986. \\
\hline 1.86 & 63037. \\
\hline 1.70 & 56409. \\
\hline 1.69 & 56413. \\
\hline 1.54 & 48729. \\
\hline 1.54 & 48999. \\
\hline 1.38 & 41478. \\
\hline 1.39 & 41466. \\
\hline 1.23 & 34876. \\
\hline 1.23 & 34852. \\
\hline 1.12 & 29004. \\
\hline 1.11 & 29121. \\
\hline 1.06 & 21148. \\
\hline 1.06 & 21114. \\
\hline 0.91 & 15505. \\
\hline 0.91 & 15527. \\
\hline 0.80 & 9663. \\
\hline 2.80 & 99423. \\
\hline 2.80 & 99377. \\
\hline 2.60 & 92369. \\
\hline 2.60 & 92358. \\
\hline 2.42 & 85416. \\
\hline 2.42 & 85405. \\
\hline 2.20 & 77618. \\
\hline 2.21 & 77630. \\
\hline 2.05 & 70634. \\
\hline 2.04 & 70586. \\
\hline 1.86 & 62913. \\
\hline 1.84 & 62886. \\
\hline 1.69 & 56225. \\
\hline 1.69 & 56541. \\
\hline 1.54 & 49080. \\
\hline 1.53 & 49012. \\
\hline 1.37 & 41847. \\
\hline 1.38 & 41791. \\
\hline 1.25 & 35501. \\
\hline 1.14 & 35539. \\
\hline 1.14 & 27522. \\
\hline 1.02 & 27462. \\
\hline 1.00 & 21508. \\
\hline & \\
\hline
\end{tabular}

\begin{tabular}{|l|l|}
\hline & \\
\hline 0.93 & 16242. \\
\hline 0.93 & 16242. \\
\hline 0.84 & 9361. \\
\hline 2.76 & 99101. \\
\hline 2.76 & 99108. \\
\hline 2.57 & 92307. \\
\hline 2.57 & 92420. \\
\hline 2.39 & 85556. \\
\hline 2.39 & 85637. \\
\hline 2.20 & 77811. \\
\hline 2.19 & 77717. \\
\hline 2.02 & 70232. \\
\hline 2.02 & 70228. \\
\hline 1.84 & 63292. \\
\hline 1.85 & 63313. \\
\hline 1.69 & 56159. \\
\hline 1.69 & 56185. \\
\hline 1.55 & 48893. \\
\hline 1.56 & 49226. \\
\hline 1.39 & 42149. \\
\hline 1.40 & 42174. \\
\hline 1.24 & 35197. \\
\hline 1.24 & 35233. \\
\hline 1.10 & 28158. \\
\hline 1.10 & 28148. \\
\hline 1.01 & 20704. \\
\hline 1.00 & 20683. \\
\hline 0.88 & 15170. \\
\hline 0.88 & 15223. \\
\hline 0.76 & 10215. \\
\hline 2.80 & 99579. \\
\hline 2.80 & 99641. \\
\hline 2.61 & 92826. \\
\hline 2.60 & 92777. \\
\hline 2.44 & 85260. \\
\hline 2.42 & 85498. \\
\hline 2.23 & 77580. \\
\hline 2.21 & 77534. \\
\hline 2.02 & 70373. \\
\hline 2.03 & 70334. \\
\hline 1.86 & 62999. \\
\hline 1.85 & 63048. \\
\hline 1.70 & 55899. \\
\hline 1.68 & 55885. \\
\hline 1.55 & 48985. \\
\hline 1.53 & 48853. \\
\hline 1.41 & 42301. \\
\hline 1.42 & 42308. \\
\hline 1.27 & 35350. \\
\hline 1.26 & 35447. \\
\hline 1.10 & 28673. \\
\hline 1.13 & 28595. \\
\hline 1.03 & 21766. \\
\hline 1.02 & 21848. \\
\hline 0.95 & 15774. \\
\hline 0.92 & 15874. \\
\hline 0.81 & 9720. \\
\hline 2.75 & 99802. \\
\hline 2.76 & 99768. \\
\hline 2.60 & 92906. \\
\hline 2.60 & 92835. \\
\hline 2.40 & 85194. \\
\hline 2.40 & 85135. \\
\hline 2.19 & 77532. \\
\hline 2.18 & 77540. \\
\hline & \\
\hline
\end{tabular}




\begin{tabular}{|c|c|c|}
\hline \multirow{12}{*}{$\frac{\vec{D}}{\bar{D}}$} & 2.03 & 70646. \\
\hline & 2.02 & 70678. \\
\hline & 1.85 & 63427. \\
\hline & 1.85 & 63420. \\
\hline & 1.69 & 56009. \\
\hline & 1.68 & 56052. \\
\hline & 1.55 & 48679. \\
\hline & 1.52 & 48323. \\
\hline & 1.39 & 42136. \\
\hline & 1.39 & 42144. \\
\hline & 1.25 & 34753. \\
\hline & 1.24 & 34785. \\
\hline & 1.10 & 28122 \\
\hline & 1.10 & 28131. \\
\hline & 1.01 & 21504. \\
\hline$\overline{\check{\sigma}}^{\circ}$ & 1.00 & 21437. \\
\hline$\underline{0}$ & 0.92 & 14754. \\
\hline$\underline{\underline{c}}$ & 0.91 & 14739. \\
\hline & 0.76 & 9594. \\
\hline$\overline{c 0}$ & 0.76 & 9577. \\
\hline
\end{tabular}

R1336mmz $(Z), T_{\mathrm{s}}=298.1 \mathrm{~K}$ File: ESPDRB.dat

\begin{tabular}{|c|c|}
\hline $\begin{array}{c}\Delta T_{\mathrm{S}} \\
(\mathrm{K})\end{array}$ & $\begin{array}{c}q^{\prime \prime} \\
\left(\mathrm{Wm}^{-2}\right)\end{array}$ \\
\hline 2.53 & 102894. \\
\hline 2.52 & 103002. \\
\hline 2.36 & 95996. \\
\hline 2.34 & 95820. \\
\hline 2.17 & 88309. \\
\hline 2.17 & 88304. \\
\hline 2.01 & 80712. \\
\hline 1.99 & 80597. \\
\hline 1.80 & 73423. \\
\hline 1.81 & 73558. \\
\hline 1.63 & 67206. \\
\hline 1.63 & 67238. \\
\hline 1.50 & 58499. \\
\hline 1.50 & 58494. \\
\hline 1.32 & 51722. \\
\hline 1.31 & 51709. \\
\hline 1.17 & 45170. \\
\hline 1.18 & 45239. \\
\hline 1.04 & 37614. \\
\hline 1.03 & 37469. \\
\hline 0.94 & 30321. \\
\hline 0.92 & 30231. \\
\hline 0.78 & 23399. \\
\hline 0.78 & 23404. \\
\hline 0.55 & 10735. \\
\hline 2.51 & 103446. \\
\hline 2.49 & 103292. \\
\hline 2.29 & 94300. \\
\hline 2.27 & 94278. \\
\hline 2.07 & 87318. \\
\hline 2.08 & 87372. \\
\hline 1.92 & 81158. \\
\hline 1.91 & 81222. \\
\hline 1.77 & 71958. \\
\hline 1.75 & 71939. \\
\hline 1.57 & 64875. \\
\hline 1.56 & 64878. \\
\hline 1.41 & 58648. \\
\hline 1.39 & 58719. \\
\hline
\end{tabular}

\begin{tabular}{|c|c|}
\hline 1.27 & 51804. \\
\hline 1.27 & 51708. \\
\hline 1.11 & 44190. \\
\hline 1.12 & 44210. \\
\hline 1.01 & 37391. \\
\hline 1.01 & 37373. \\
\hline 0.96 & 29425. \\
\hline 0.95 & 29367. \\
\hline 0.78 & 22629. \\
\hline 0.77 & 22568. \\
\hline 0.53 & 10866. \\
\hline 2.54 & 102891. \\
\hline 2.54 & 102847. \\
\hline 2.34 & 95459. \\
\hline 2.33 & 95417. \\
\hline 2.14 & 88420. \\
\hline 2.13 & 88461. \\
\hline 1.96 & 80991. \\
\hline 1.97 & 81004. \\
\hline 1.79 & 74003. \\
\hline 1.80 & 74131. \\
\hline 1.64 & 66813. \\
\hline 1.65 & 66840. \\
\hline 1.45 & 58021. \\
\hline 1.44 & 57950. \\
\hline 1.25 & 50800. \\
\hline 1.27 & 50834. \\
\hline 1.13 & 44446. \\
\hline 1.12 & 44501. \\
\hline 0.99 & 37513. \\
\hline 0.99 & 37552. \\
\hline 0.87 & 30356. \\
\hline 0.87 & 30375. \\
\hline 0.80 & 22947. \\
\hline 0.81 & 22922. \\
\hline 0.69 & 16281. \\
\hline 0.69 & 16256. \\
\hline 0.53 & 10503. \\
\hline 2.47 & 101562. \\
\hline 2.47 & 101500. \\
\hline 2.28 & 94777. \\
\hline 2.29 & 94830. \\
\hline 2.10 & 87278. \\
\hline 2.10 & 87261. \\
\hline
\end{tabular}

\begin{tabular}{|c|c|}
\hline 1.90 & 80478. \\
\hline 1.91 & 80623. \\
\hline 1.75 & 73023. \\
\hline 1.76 & 72961. \\
\hline 1.58 & 65893. \\
\hline 1.58 & 65859. \\
\hline 1.41 & 59357. \\
\hline 1.41 & 59410. \\
\hline 1.26 & 51520. \\
\hline 1.25 & 51464. \\
\hline 1.10 & 43983. \\
\hline 1.09 & 44048. \\
\hline 0.96 & 36873. \\
\hline 0.95 & 36921. \\
\hline 0.82 & 30061. \\
\hline 0.81 & 30070. \\
\hline 0.76 & 22895. \\
\hline 0.77 & 22772. \\
\hline 0.69 & 15785. \\
\hline 0.70 & 15763. \\
\hline 0.53 & 9655. \\
\hline 2.52 & 101254. \\
\hline 2.51 & 101234. \\
\hline 2.31 & 94509. \\
\hline 2.31 & 94521. \\
\hline 2.15 & 88300. \\
\hline 2.14 & 88473. \\
\hline 1.98 & 79907. \\
\hline 1.97 & 79893. \\
\hline 1.79 & 72949. \\
\hline 1.77 & 72975. \\
\hline 1.62 & 66887. \\
\hline 1.61 & 66920. \\
\hline 1.43 & 58139. \\
\hline 1.43 & 58245. \\
\hline 1.25 & 50863. \\
\hline 1.25 & 50855. \\
\hline 1.06 & 44212. \\
\hline 1.06 & 44334. \\
\hline 0.95 & 37401. \\
\hline 0.95 & 37432. \\
\hline 0.85 & 30160. \\
\hline 0.86 & 30114. \\
\hline 0.76 & 22976. \\
\hline
\end{tabular}




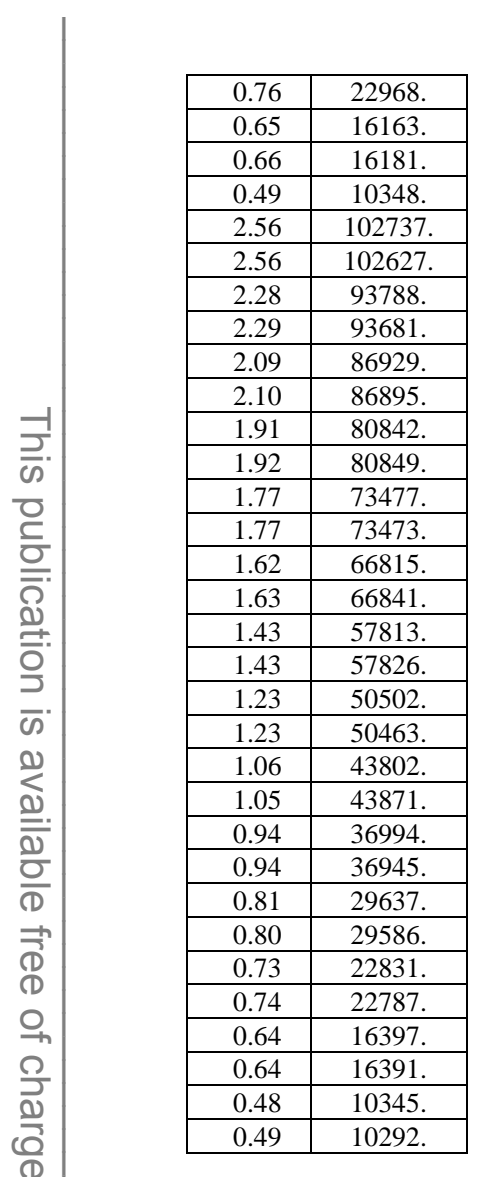

\begin{tabular}{|c|c|}
\hline 0.66 & 9198. \\
\hline 2.95 & 103614. \\
\hline 2.95 & 103774. \\
\hline 2.71 & 95370. \\
\hline 2.70 & 95435. \\
\hline 2.52 & 88050. \\
\hline 2.53 & 87993. \\
\hline 2.36 & 80112. \\
\hline 2.35 & 80086. \\
\hline 2.14 & 72666. \\
\hline 2.15 & 72584. \\
\hline 1.94 & 65260. \\
\hline 1.94 & 65159. \\
\hline 1.74 & 58237. \\
\hline 1.74 & 58241. \\
\hline 1.55 & 51944. \\
\hline 1.54 & 52029. \\
\hline 1.40 & 45060. \\
\hline 1.39 & 45056. \\
\hline 1.23 & 37581. \\
\hline 1.22 & 37547. \\
\hline 1.06 & 29734. \\
\hline 1.05 & 29716. \\
\hline 0.88 & 22255. \\
\hline 0.90 & 22221. \\
\hline 0.75 & 15435. \\
\hline 0.76 & 15402. \\
\hline 0.53 & 9406. \\
\hline 2.98 & 105682. \\
\hline 2.98 & 105664. \\
\hline 2.72 & 93659. \\
\hline 2.72 & 93581. \\
\hline & \\
\hline
\end{tabular}

\begin{tabular}{|l|l|}
\hline 2.49 & 86433. \\
\hline 2.47 & 86448. \\
\hline 2.26 & 79839. \\
\hline 2.26 & 79875. \\
\hline 2.11 & 74091. \\
\hline 2.09 & 7411. \\
\hline 1.92 & 67159. \\
\hline 1.91 & 67169. \\
\hline 1.80 & 59166. \\
\hline 1.82 & 59085. \\
\hline 1.65 & 51090. \\
\hline 1.66 & 51003. \\
\hline 1.44 & 43418. \\
\hline 1.43 & 43315. \\
\hline 1.15 & 36157. \\
\hline 1.16 & 36065. \\
\hline 0.92 & 29081. \\
\hline 0.92 & 29026. \\
\hline 0.73 & 22544. \\
\hline 0.72 & 22602. \\
\hline 0.61 & 17415. \\
\hline 0.63 & 17333. \\
\hline 0.58 & 10831. \\
\hline 2.96 & 103968. \\
\hline 2.97 & 104168. \\
\hline 2.74 & 96095. \\
\hline 2.77 & 96191. \\
\hline 2.54 & 87997. \\
\hline 2.54 & 87821. \\
\hline 2.35 & 80382. \\
\hline 2.34 & 80268. \\
\hline 2.14 & 73025. \\
\hline
\end{tabular}




\begin{tabular}{|c|c|}
\hline \multirow{2}{*}{$\begin{array}{l}2.13 \\
1.95\end{array}$} & 72869. \\
\hline & 65783. \\
\hline 1.94 & 65795. \\
\hline 1.77 & 58704. \\
\hline 1.77 & 58659. \\
\hline 1.57 & 51521. \\
\hline 1.57 & 51542. \\
\hline 1.37 & 44628. \\
\hline 1.36 & 44633. \\
\hline 1.18 & 37542. \\
\hline 1.19 & 37495 . \\
\hline 1.01 & 30405. \\
\hline 1.01 & 30445. \\
\hline 0.88 & 23485 . \\
\hline 0.86 & 23496. \\
\hline 0.75 & 16693. \\
\hline 0.74 & 16649. \\
\hline 0.55 & 10611. \\
\hline 3.02 & 104131. \\
\hline 3.02 & 103979. \\
\hline 2.72 & 94139. \\
\hline 2.72 & 94163. \\
\hline 2.52 & 86914. \\
\hline 2.51 & 86937. \\
\hline 2.32 & 79788. \\
\hline 2.31 & 79799. \\
\hline 2.13 & 72876. \\
\hline 2.13 & 72843. \\
\hline 1.96 & 65796. \\
\hline 1.95 & 65691. \\
\hline 1.78 & 58301. \\
\hline 1.77 & 58283. \\
\hline 1.56 & 51257. \\
\hline 1.56 & 51217. \\
\hline 1.36 & 44441. \\
\hline 1.36 & 44364. \\
\hline 1.15 & 37964. \\
\hline 1.15 & 37976. \\
\hline 1.00 & 30927. \\
\hline 1.01 & 30853. \\
\hline 0.85 & 23857. \\
\hline 0.86 & 23842. \\
\hline 0.77 & 16565. \\
\hline 0.75 & 16594. \\
\hline 0.54 & 10662. \\
\hline 2.99 & 103583. \\
\hline 3.00 & 103496. \\
\hline 2.71 & 93710. \\
\hline 2.71 & 93794. \\
\hline 2.51 & 86641. \\
\hline 2.51 & 86620. \\
\hline 2.32 & 79564. \\
\hline 2.32 & 79562. \\
\hline 2.13 & 72412. \\
\hline 2.13 & 72402 . \\
\hline 1.96 & 65224. \\
\hline 1.95 & 65168. \\
\hline 1.74 & 58124. \\
\hline 1.74 & 58120. \\
\hline 1.57 & 51046. \\
\hline 1.56 & 51021. \\
\hline 1.36 & 44044. \\
\hline 1.37 & 44045 . \\
\hline 1.18 & 37222. \\
\hline 1.18 & 37189. \\
\hline
\end{tabular}

\begin{tabular}{|c|c|}
\hline 0.99 & 30318. \\
\hline 1.04 & 29777. \\
\hline 0.83 & 22952. \\
\hline 0.83 & 22916. \\
\hline 0.73 & 16375. \\
\hline 0.74 & 16390. \\
\hline 0.64 & 9414. \\
\hline 0.59 & 10547. \\
\hline
\end{tabular}


Table 3 Number of test days and data points

\begin{tabular}{|c|c|c|}
\hline Fluid $\left[T_{\mathrm{s}}\right]$ & Number of days & $\begin{array}{c}\text { Number of data points/ } \\
\text { Number of data points with } \\
\text { outliers removed }\end{array}$ \\
\hline $\mathrm{R} 123[277.6 \mathrm{~K}]$ & 7 & $189 / 183$ \\
$0.7 \mathrm{~K} \leq \Delta T_{\mathrm{s}} \leq 2.7 \mathrm{~K}$ & 14 & $378 / 371$ \\
\hline $\mathrm{R} 1336 \mathrm{mmz}(\mathrm{Z})[277.6 \mathrm{~K}]$ & & $158 / 154$ \\
$0.9 \mathrm{~K} \leq \Delta T_{\mathrm{s}} \leq 2.9 \mathrm{~K}$ & 6 & $162 / 157$ \\
\hline $\mathrm{R} 1336 \mathrm{mmz}(\mathrm{Z})[298.1 \mathrm{~K}]$ & & \\
$0.5 \mathrm{~K} \leq \Delta T_{\mathrm{s}} \leq 2.5 \mathrm{~K}$ & 6 & \\
\hline $\mathrm{R} 1336 \mathrm{mmz}(\mathrm{Z})[318.1 \mathrm{~K}]$ & & \\
$0.6 \mathrm{~K} \leq \Delta T_{\mathrm{s}} \leq 3.0 \mathrm{~K}$ & & \\
\hline
\end{tabular}


Table 4 Estimated parameters for cubic boiling curve fits

$$
\Delta T_{\mathrm{s}}=\mathrm{A}_{0}+\mathrm{A}_{1} q " \mathrm{~A}_{2} q^{, 2}+\mathrm{A}_{3} q^{\prime \prime 3}
$$

$\Delta T_{\mathrm{s}}$ in kelvin and $q$ " in $\mathrm{Wm}^{-2}$

\begin{tabular}{|c|c|c|c|c|}
\hline Fluid $\left[T_{\mathrm{s}}\right]$ & $\mathrm{A}_{\mathrm{o}}$ & $\mathrm{A}_{1}$ & $\mathrm{~A}_{2}$ & $\mathrm{~A}_{3}$ \\
\hline $\mathrm{R} 123[277.6 \mathrm{~K}]$ & & & & \\
$0.7 \mathrm{~K} \leq \Delta T_{\mathrm{s}} \leq 2.7 \mathrm{~K}$ & 0.4328115 & $3.600867 \times 10^{-5}$ & $-3.226015 \times 10^{-10}$ & $2.062701 \times 10^{-15}$ \\
\hline $\begin{array}{c}\mathrm{R} 1336 \mathrm{mmz}(\mathrm{Z})[277.6 \mathrm{~K}] \\
0.9 \mathrm{~K} \leq \Delta T_{\mathrm{s}} \leq 2.9 \mathrm{~K}\end{array}$ & 0.6904033 & $1.698677 \times 10^{-5}$ & $4.601907 \times 10^{-11}$ & $9.439836 \times 10^{-17}$ \\
\hline $\begin{array}{c}\mathrm{R} 1336 \mathrm{mmz}(\mathrm{Z})[298.1 \mathrm{~K}] \\
0.5 \mathrm{~K} \leq \Delta T_{\mathrm{s}} \leq 2.5 \mathrm{~K}\end{array}$ & 0.4668658 & $9.437844 \times 10^{-6}$ & $1.384232 \times 10^{-10}$ & $-3.429342 \times 10^{-16}$ \\
\hline $\begin{array}{c}\mathrm{R} 1336 \mathrm{mmz}(\mathrm{Z})[318.1 \mathrm{~K}] \\
0.6 \mathrm{~K} \leq \Delta T_{\mathrm{s}} \leq 3.0 \mathrm{~K}\end{array}$ & 0.3493537 & $2.063197 \times 10^{-5}$ & $6.325774 \times 10^{-11}$ & $-2.038218 \times 10^{-16}$ \\
\hline
\end{tabular}


Table 5 Residual standard deviation of $\Delta T_{\mathrm{s}}$

\begin{tabular}{|c|c|}
\hline Fluid $\left[T_{\mathrm{s}}\right]$ & $(\mathrm{K})$ \\
\hline $\mathrm{R} 123[277.6 \mathrm{~K}]$ & \\
$0.7 \mathrm{~K} \leq \Delta T_{\mathrm{s}} \leq 2.7 \mathrm{~K}$ & 0.04 \\
\hline $\mathrm{R} 1336 \mathrm{mmz}(\mathrm{Z})[277.6 \mathrm{~K}]$ & \\
$0.9 \mathrm{~K} \leq \Delta T_{\mathrm{s}} \leq 2.9 \mathrm{~K}$ & 0.11 \\
\hline $\mathrm{R} 1336 \mathrm{mmz}(\mathrm{Z})[298.1 \mathrm{~K}]$ & \\
$0.5 \mathrm{~K} \leq \Delta T_{\mathrm{s}} \leq 2.5 \mathrm{~K}$ & 0.03 \\
\hline $\mathrm{R} 1336 \mathrm{mmz}(\mathrm{Z})[318.1 \mathrm{~K}]$ & \\
$0.6 \mathrm{~K} \leq \Delta T_{\mathrm{s}} \leq 3.0 \mathrm{~K}$ & 0.05 \\
\hline
\end{tabular}


Table 6 Average magnitude of $95 \%$ multi-use confidence interval for mean $\Delta T_{\mathrm{s}}$

\begin{tabular}{|c|c|}
\hline Fluid $\left[T_{\mathrm{s}}\right]$ & $U(\mathrm{~K})$ \\
\hline $\mathrm{R} 123[277.6 \mathrm{~K}]$ & \\
$0.7 \mathrm{~K} \leq \Delta T_{\mathrm{s}} \leq 2.7 \mathrm{~K}$ & 0.02 \\
\hline $\mathrm{R} 1336 \mathrm{mmz}(\mathrm{Z})[277.6 \mathrm{~K}]$ & \\
$0.9 \mathrm{~K} \leq \Delta T_{\mathrm{s}} \leq 2.9 \mathrm{~K}$ & 0.04 \\
\hline $\mathrm{R} 1336 \mathrm{mmz}(\mathrm{Z})[298.1 \mathrm{~K}]$ & \\
$0.5 \mathrm{~K} \leq \Delta T_{\mathrm{s}} \leq 2.5 \mathrm{~K}$ & 0.02 \\
\hline $\mathrm{R} 1336 \mathrm{mmz}(\mathrm{Z})[318.1 \mathrm{~K}]$ & \\
$0.6 \mathrm{~K} \leq \Delta T_{\mathrm{s}} \leq 3.0 \mathrm{~K}$ & 0.03 \\
\hline
\end{tabular}


Table 7 Selected fluid properties of test refrigerants at saturation (Lemmon et al., 2018)

\begin{tabular}{|c|c|c|c|c|c|c|c|c|c|}
\hline Fluid & $\begin{array}{c}T_{\mathrm{s}} \\
(\mathrm{K})\end{array}$ & $\begin{array}{c}P_{\mathrm{v}} \\
(\mathrm{kPa})\end{array}$ & $\begin{array}{c}k_{\mathrm{l}} \\
\left(\mathrm{mWm} \mathrm{K}^{-1}\right)\end{array}$ & $\begin{array}{c}\mu \mathrm{l} \\
\left(\mu \mathrm{kg} \cdot \mathrm{m}^{-1} \cdot \mathrm{s}^{-1}\right)\end{array}$ & $\begin{array}{c}\sigma \\
\left(\mathrm{N} \cdot \mathrm{m}^{-1}\right)\end{array}$ & $\begin{array}{c}\rho_{\mathrm{l}} \\
\left(\mathrm{kg} \mathrm{m}^{-3}\right)\end{array}$ & $\begin{array}{c}\rho_{\mathrm{v}} \\
\left(\mathrm{kg} \mathrm{m}^{-3}\right)\end{array}$ & $\begin{array}{c}h_{\mathrm{fg}} \\
\left(\mathrm{kJ} \mathrm{kg}^{-1}\right)\end{array}$ & $\begin{array}{c}c_{\mathrm{pl}} \\
\left(\mathrm{kJkg}^{-1} \mathrm{~K}^{-1}\right)\end{array}$ \\
\hline R123 & 277.6 & 39.85 & 82.387 & 533.98 & 0.017654 & 1515.3 & 2.7 & 179.69 & 0.9953 \\
\hline R1336mmz(Z) & 277.6 & 30.58 & 76.539 & 467.22 & 0.018161 & 1416.9 & 2.2 & 177.56 & 1.1784 \\
\hline R1336mmz(Z) & 298.1 & 73.42 & 72.143 & 363.71 & 0.015478 & 1364.8 & 5.1 & 168.50 & 1.2206 \\
\hline R1336mmz(Z) & 318.1 & 151.63 & 68.045 & 289.45 & 0.012938 & 1311.2 & 10.1 & 159.03 & 1.2627 \\
\hline
\end{tabular}




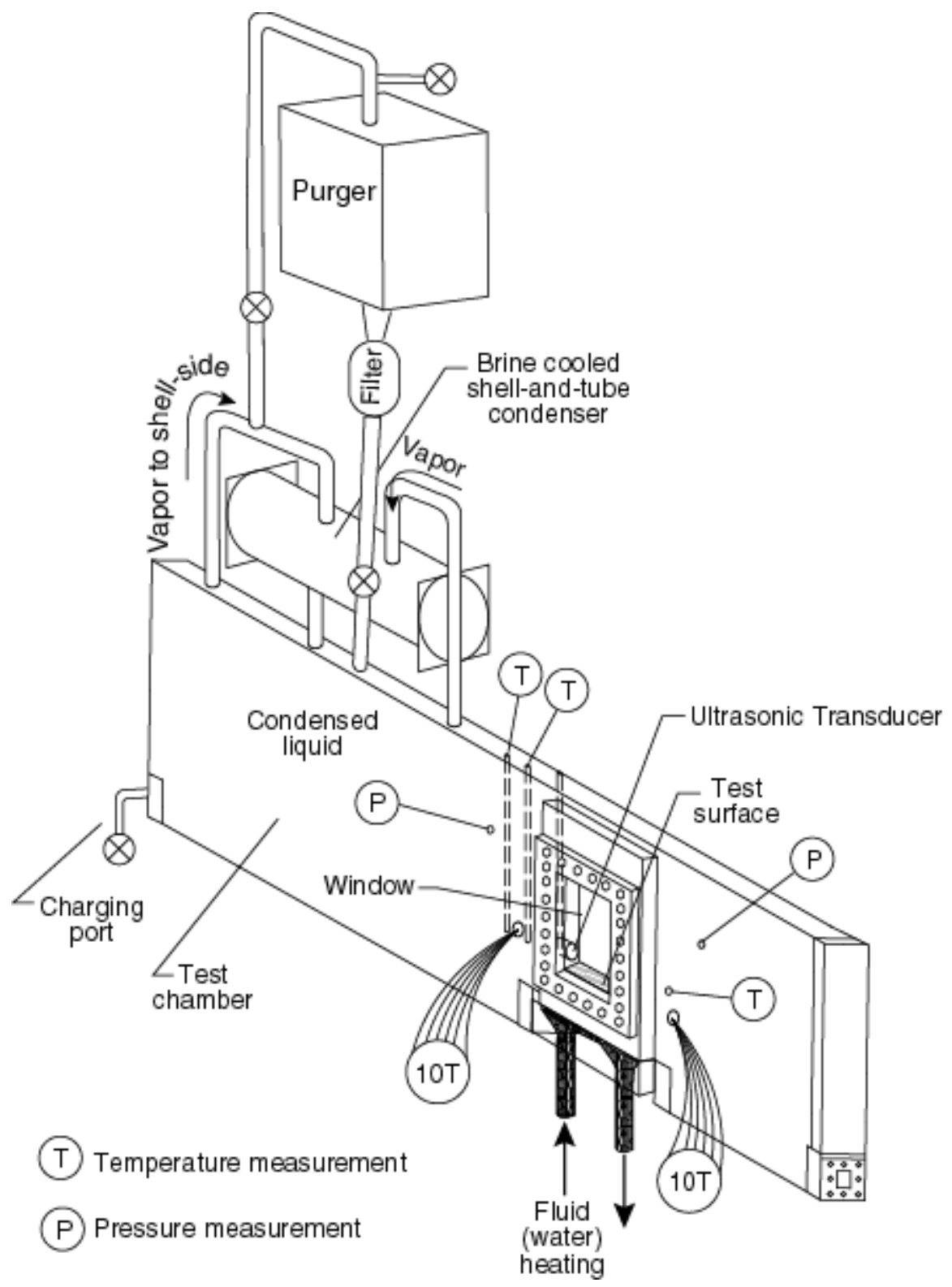

Fig. 1 Schematic of test apparatus 


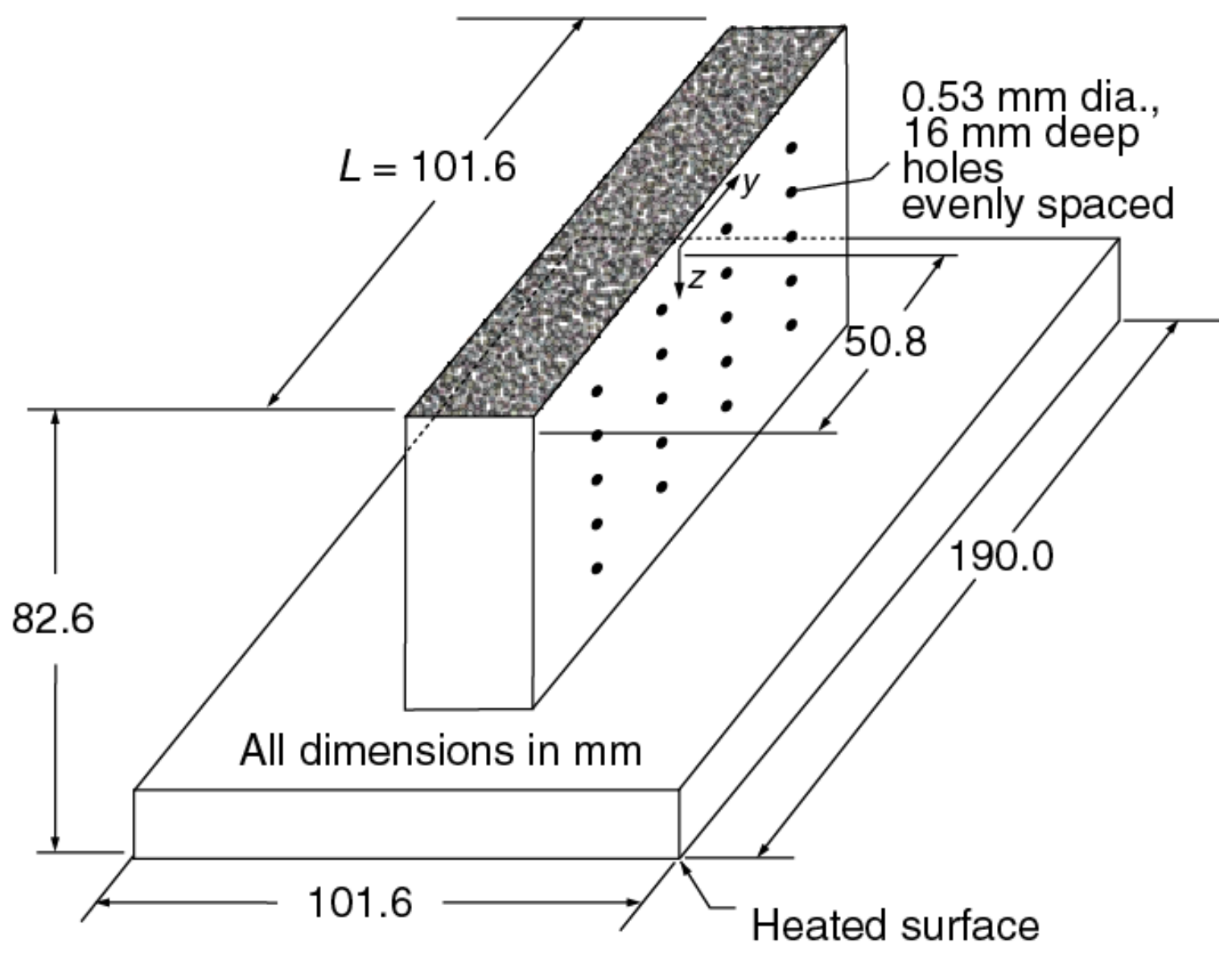

Fig. 2 OFHC copper flat test plate with Turbo-ESP surface and thermocouple coordinate system 


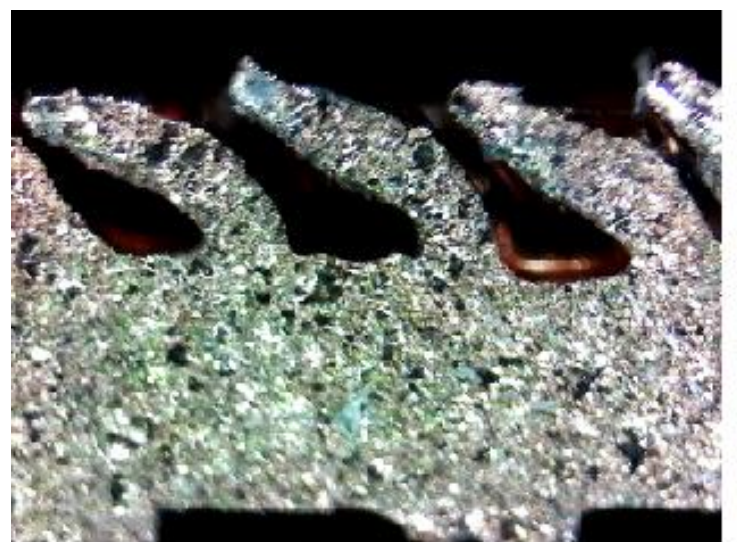

$-0.1 \mathrm{~mm}$

SIDE VIEW

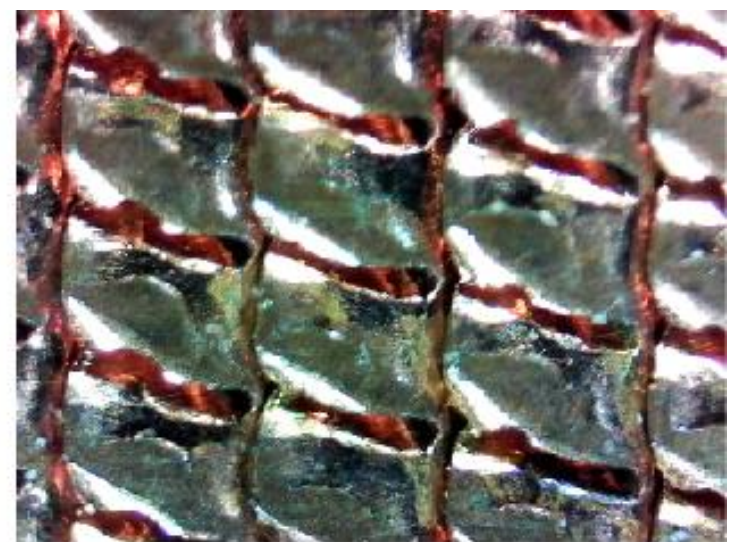

$-0.1 \mathrm{~mm}$

Fig. 3 Photograph of Turbo-ESP surface 


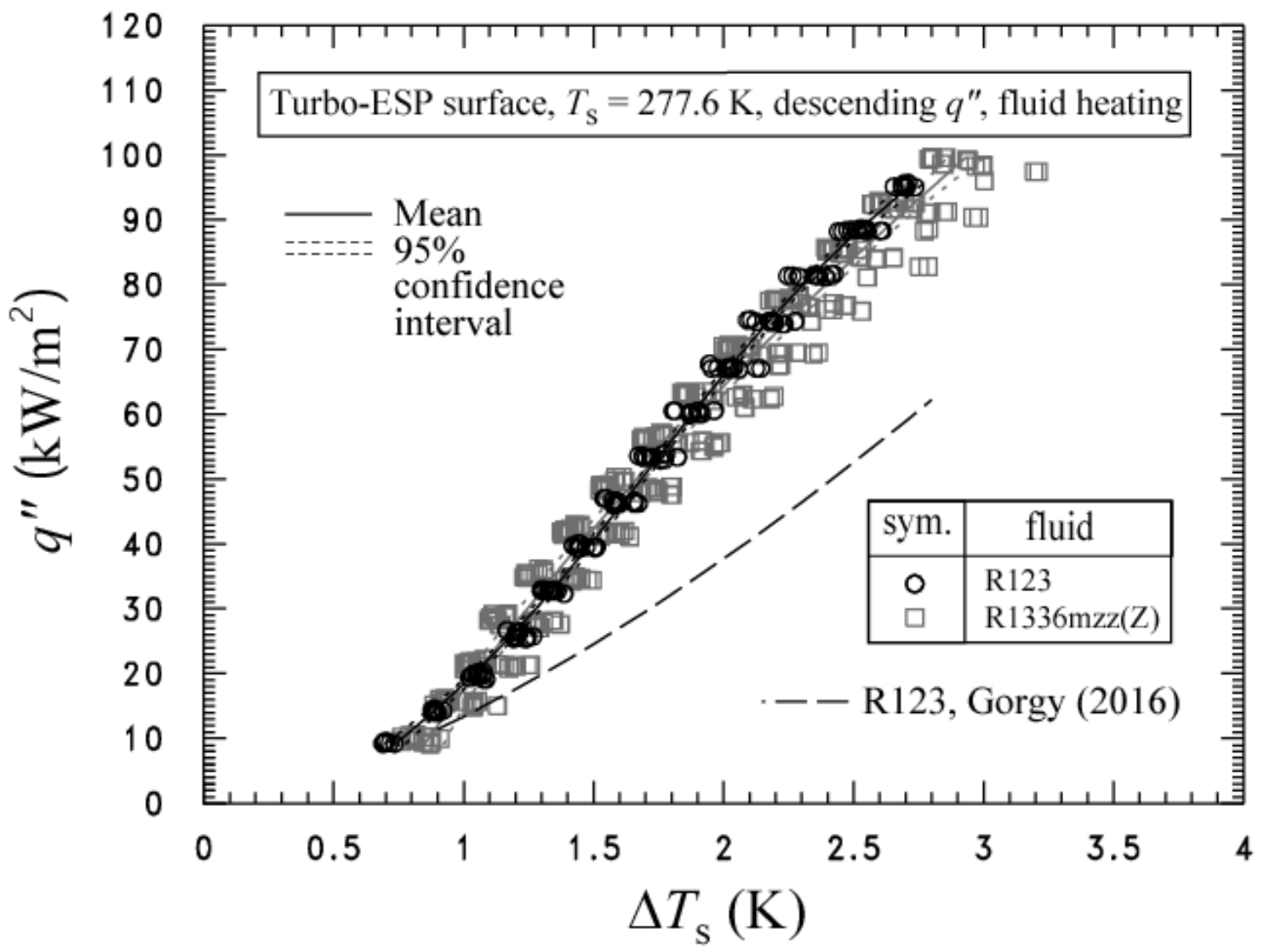

Fig. 4 Comparison of boiling curves for $R 123$ and $R 1336 m z z(Z)$ at $277.6 \mathrm{~K}$ 


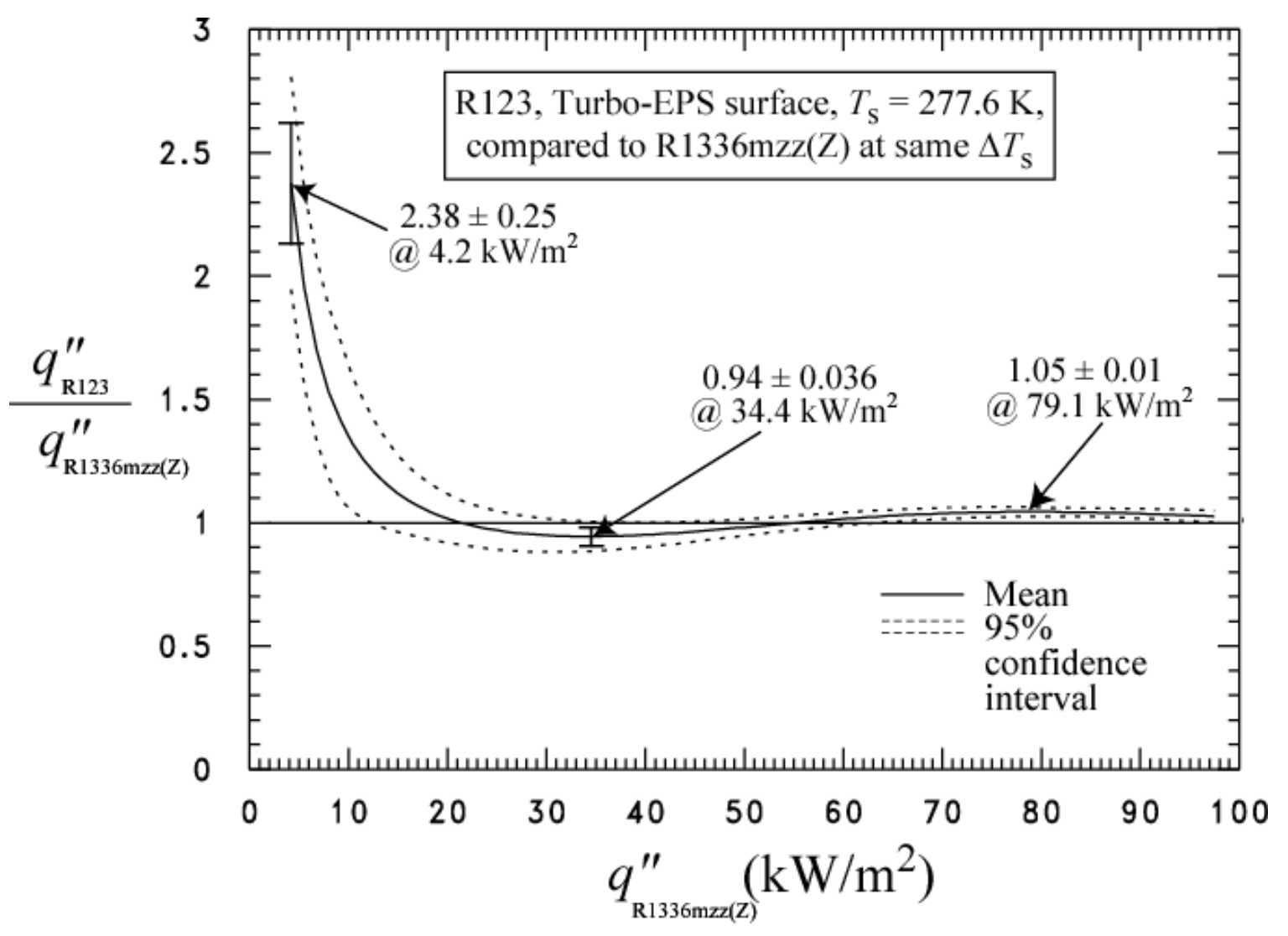

Fig. 5 Comparison of $R 123$ heat flux to that for $R 1336 m z z(Z)$ at the same wall superheat 


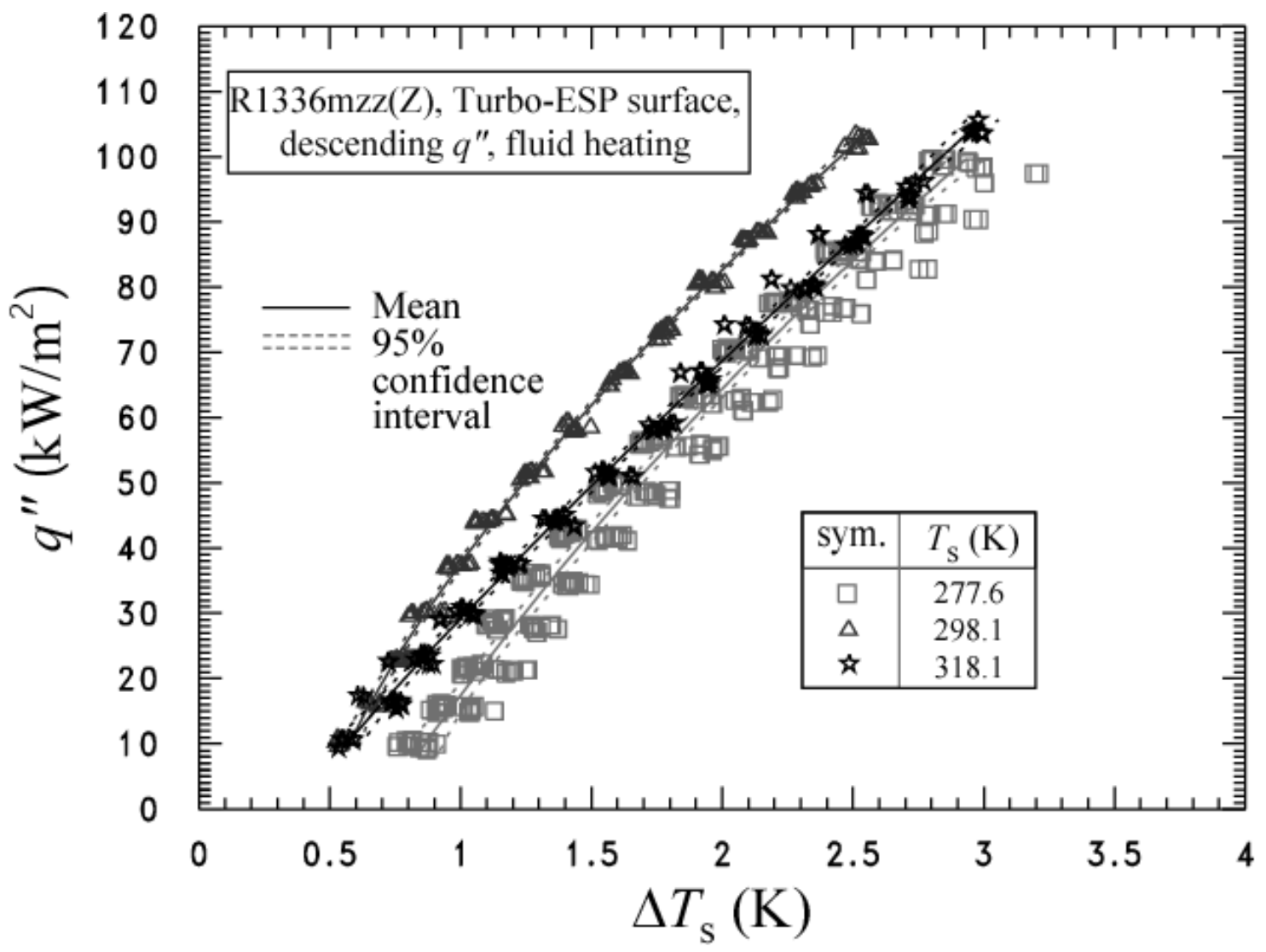

Fig. 6 Boiling curves for $R 1336 m z z(Z)$ at different saturation temperatures 


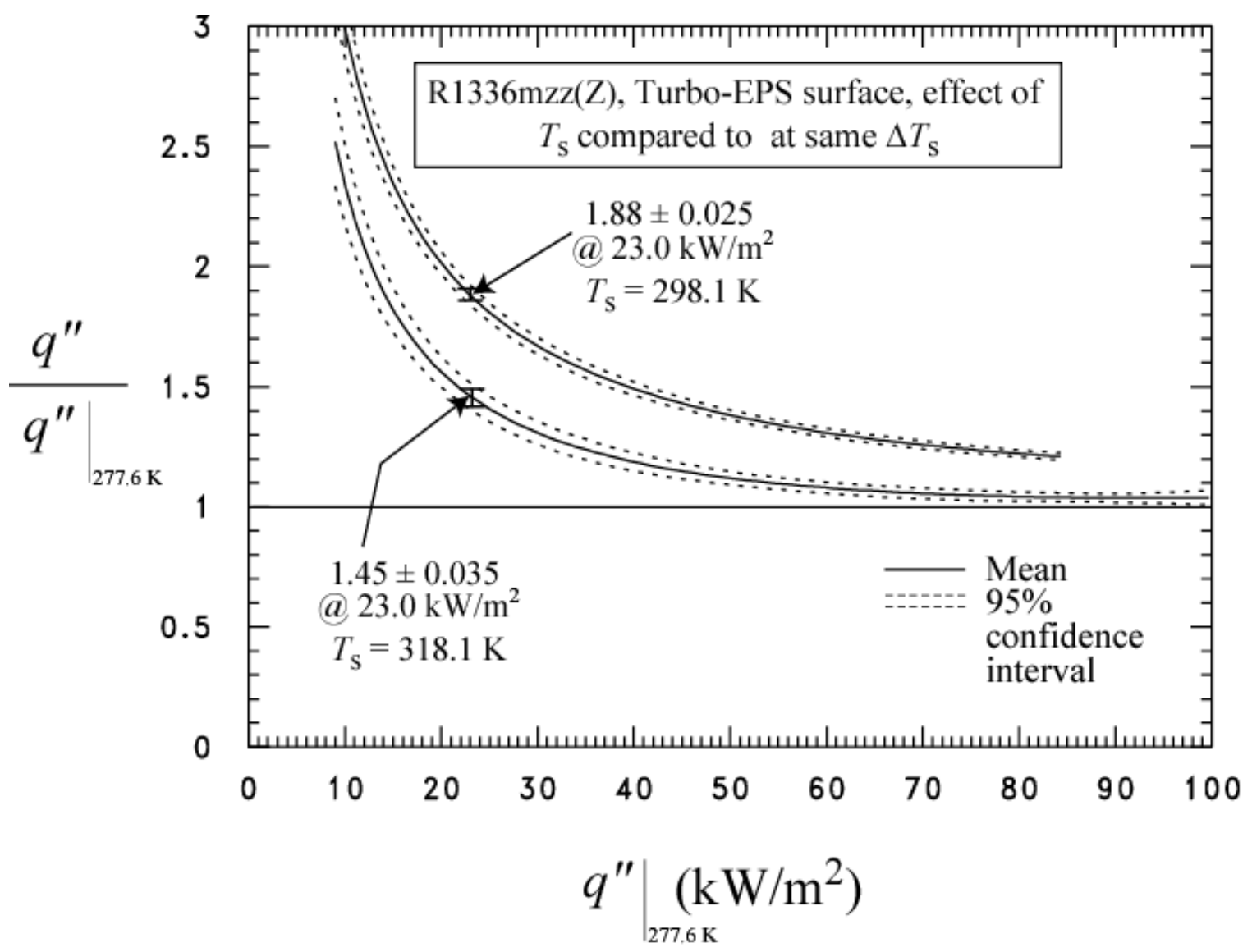

Fig. 7 Comparison of pool boiling model to $R 1336 \mathrm{mzz}(Z)$ for different saturation temperatures 


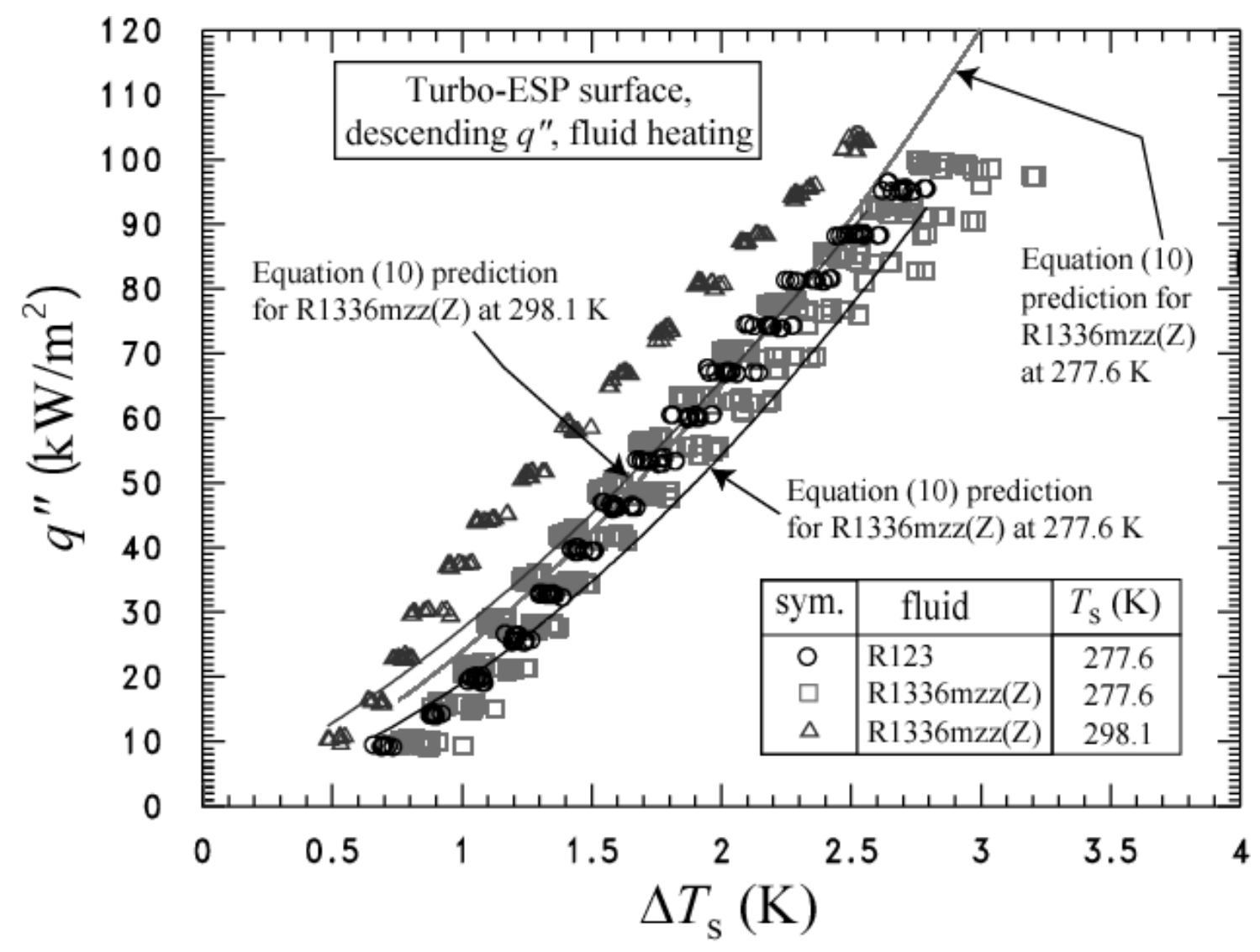

Fig. 8 Comparison of pool boiling model for Turbo-ESP surface to present measurements for $R 123$ and $R 1336 \mathrm{mzz}(Z)$ 


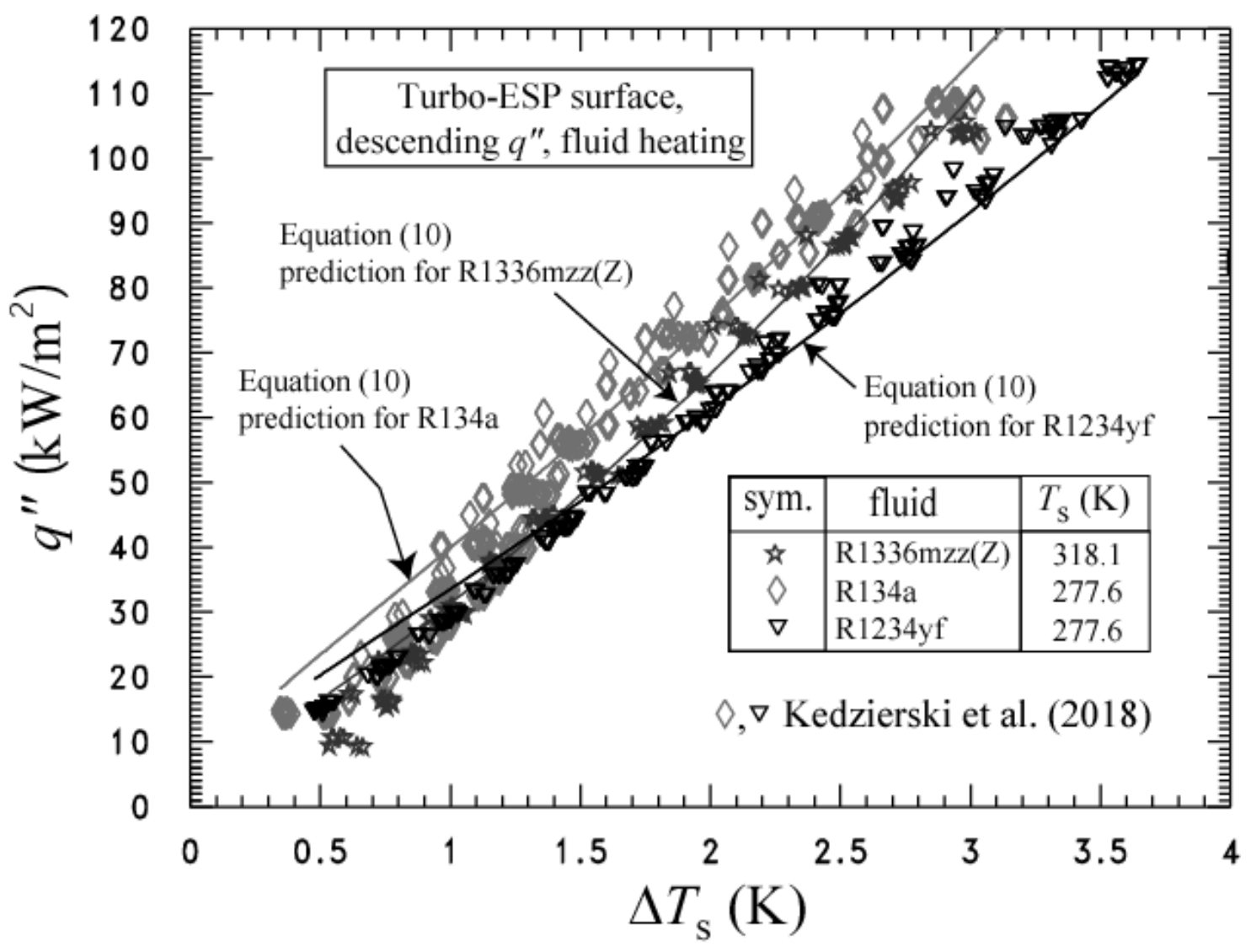

Fig. 9 Comparison of pool boiling model for Turbo-ESP surface to present measurements for $R 1336 \mathrm{mzz}(\mathrm{Z})$, and Kedzierski et al. (2018) measurements for R134a and R1234yf 


\section{APPENDIX A: UNCERTAINTIES}

Figure A.1 shows the expanded relative (percent) uncertainty of the heat flux $\left(U_{\mathrm{q}}\right)$ as a function of the heat flux. Figure A.2 shows the expanded uncertainty of the wall temperature as a function of the heat flux. The uncertainties shown in Figs. A.1 and A.2 are "within-run uncertainties." These do not include the uncertainties due to "betweenrun effects" or differences observed between tests taken on different days. The "withinrun uncertainties" include only the random effects and uncertainties associated with one particular test. All other uncertainties reported in this study are "between-run uncertainties" which include all random effects such as surface past history or seeding.

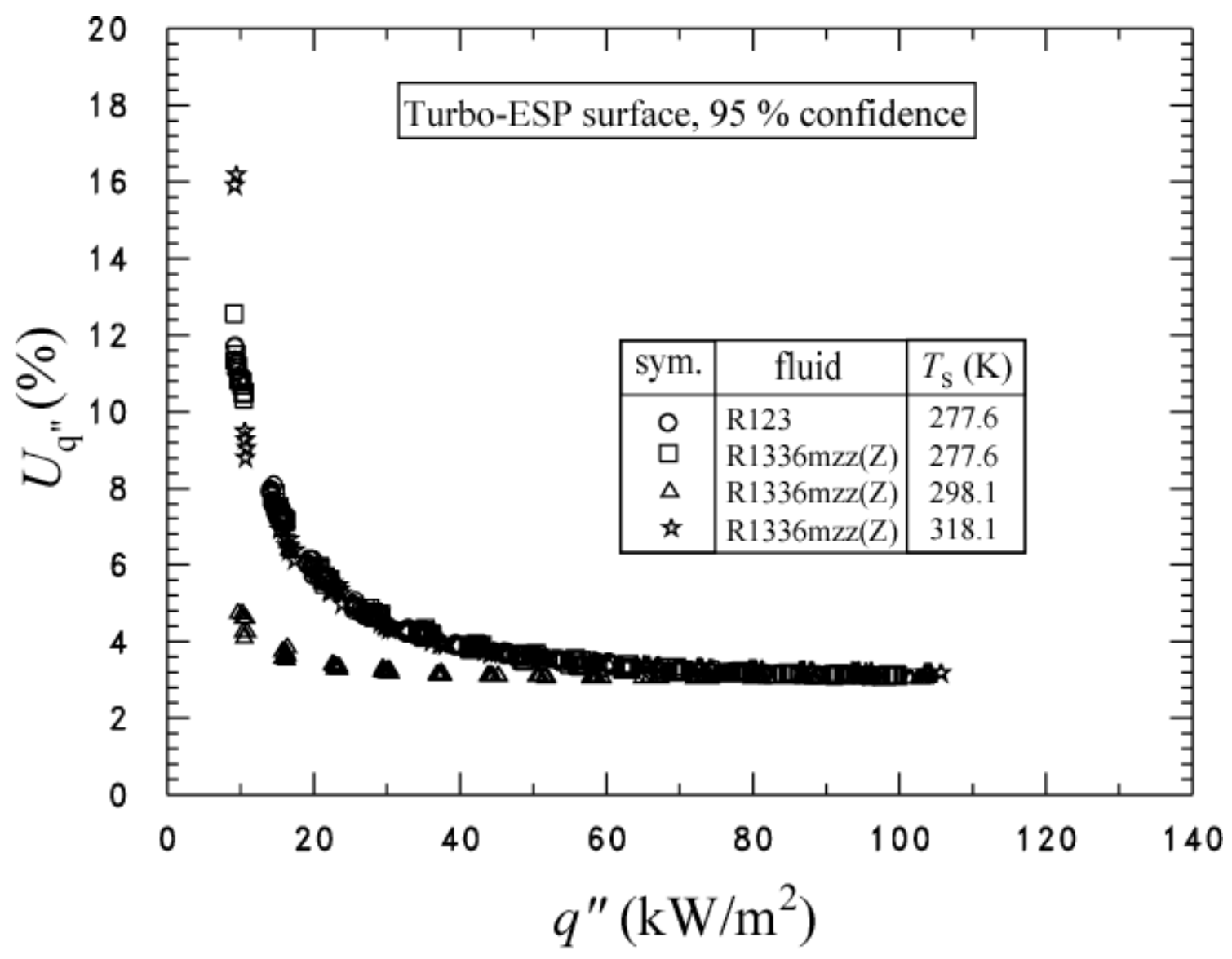

Fig. A.1 Expanded relative uncertainty in the heat flux of the surface at the $95 \%$ confidence level 


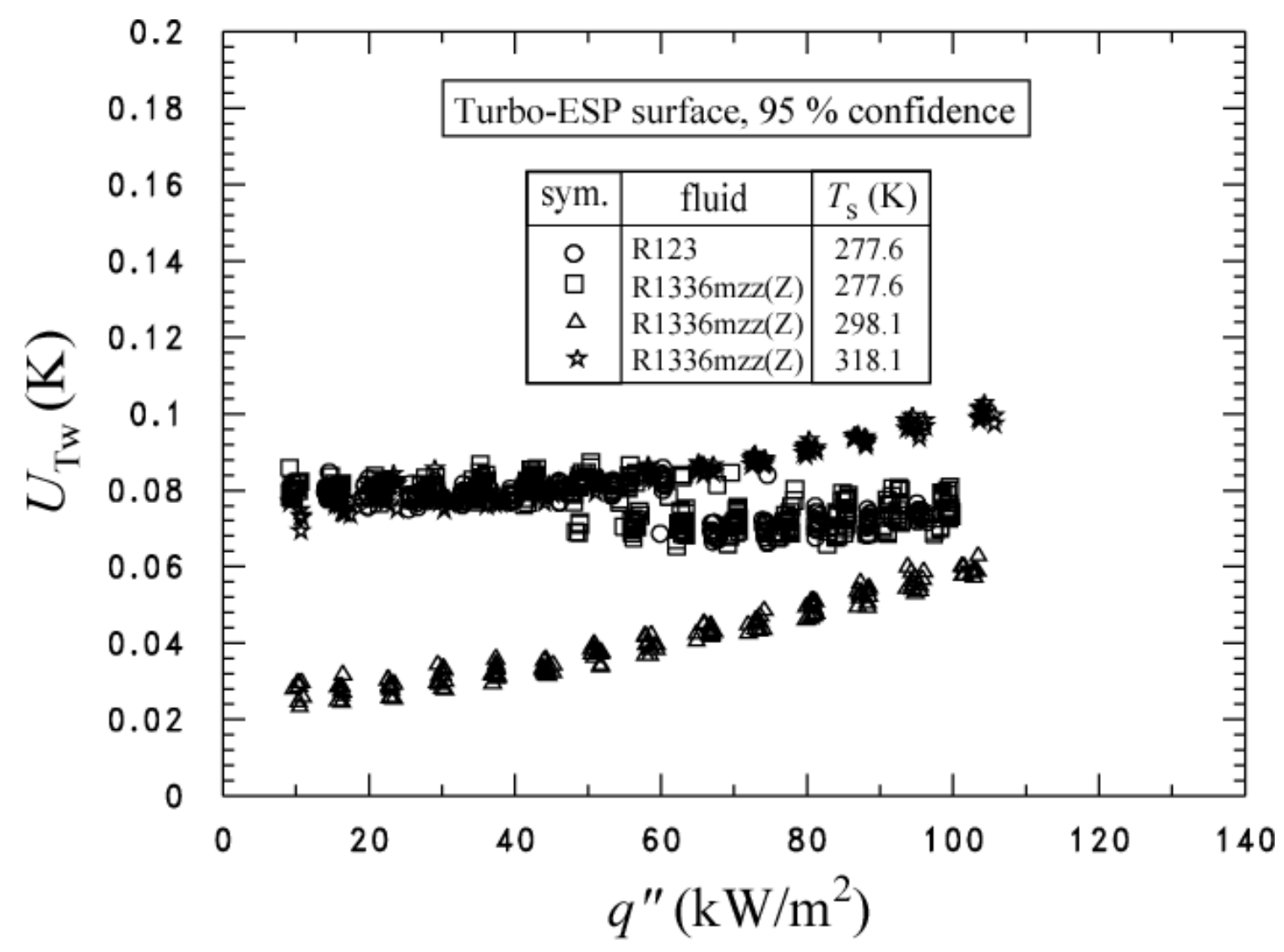

Fig. A.2 Expanded uncertainty in the temperature of the surface at the $95 \%$ confidence level 